\title{
Article
}

\section{FDIONIC18 Interactions and stabilisation of acetone, sulfur dioxide and water with 1-octyl-3-methylimidazolium tetrafluoroborate at low temperatures}

Buckley, Matthew, Syres, Karen and Jones, Robert G.

Available at http://clok.uclan.ac.uk/18269/

Buckley, Matthew, Syres, Karen ORCID: 0000-0001-7439-475X and Jones, Robert G. (2017) FDIONIC18 Interactions and stabilisation of acetone, sulfur dioxide and water with 1-octyl-3-methylimidazolium tetrafluoroborate at low temperatures. Faraday Discussions . ISSN 1359-6640

It is advisable to refer to the publisher's version if you intend to cite from the work. http://dx.doi.org/10.1039/C7FD00146K

For more information about UCLan's research in this area go to http://www.uclan.ac.uk/researchgroups/ and search for <name of research Group>.

For information about Research generally at UCLan please go to http://www.uclan.ac.uk/research/

All outputs in CLoK are protected by Intellectual Property Rights law, including Copyright law. Copyright, IPR and Moral Rights for the works on this site are retained by the individual authors and/or other copyright owners. Terms and conditions for use of this material are defined in the policies page. 
Interactions and stabilisation of acetone, sulfur dioxide and water with 1-octyl-3methylimidazolium tetrafluoroborate $[\mathrm{OMIM}]\left[\mathrm{BF}_{4}\right]$ at low temperatures.

\author{
Matthew Buckley, Karen L. Syres†, Robert G. Jones*
}

Department of Physical Chemistry, School of Chemistry, University of Nottingham, Nottingham NG7 2RD

$\uparrow$ Current address: Jeremiah Horrocks Institute, University of Central Lancashire, Fylde Road, Preston, PR1 2HE

* robert.g.jones@nottingham.ac.uk

\title{
Abstract
}

The interactions between three small molecules, water $\left(\mathrm{H}_{2} \mathrm{O}\right)$, sulfur dioxide $\left(\mathrm{SO}_{2}\right)$ and acetone ( ( $\left.\mathrm{CH}_{3}\right)_{2} \mathrm{CO}$ ) with the ionic liquid (IL) 1-octyl-3-methylimidazolium tetrafluoroborate, [OMIM] [BF 4 , have been determined using line of sight temperature programmed desorption (LOSTPD) from a gold surface. Multilayers of the IL were deposited by physical vapour deposition with multilayers of the small molecular species (adsorbed from the gas phase) at $90 \mathrm{~K}$. LOSTPD was then carried out with the small molecular species desorbing first from the mixed multilayer, followed at higher temperatures by desorption of the IL from the gold surface. The IL had a high activation energy for desorption of $126(6) \mathrm{kJ} \mathrm{mol}^{-1}$. Pure acetone showed a desorption activation energy of 38(2) kJ mol1 , which increased to $45-61 \mathrm{~kJ} \mathrm{~mol}^{-1}$ when it was pre-adsorbed below an overlying porous layer of the ionic liquid at $90 \mathrm{~K}$. The stabilised acetone is thought to be associated with pores containing ionic moieties. Destabilised acetone was also observed and thought to originate from pores containing octyl chains. The quantity of stabilised acetone scaled with the amount of IL, being $\approx 1.1$ molecules per IL ion pair. $\mathrm{SO}_{2}$ and $\mathrm{H}_{2} \mathrm{O}$ were co-adsorbed with the IL at $90 \mathrm{~K}$ leading to an intimate mixture of the two. For pure $\mathrm{SO}_{2}$ the desorption energy was $32(2) \mathrm{kJ} \mathrm{mol}^{-1}$, which increased to 40 $50 \mathrm{~kJ} \mathrm{~mol}^{-1}$ for relative concentrations up to $6 \mathrm{SO}_{2}$ molecules per IL ion pair. For pure water the activation energies were $49(5) \mathrm{kJ} \mathrm{mol}^{-1}$ and 43(1) $\mathrm{kJ} \mathrm{mol}^{-1}$ for amorphous and crystalline ice respectively. When co-adsorbed with the IL the stabilisation energies were $42-49 \mathrm{~kJ} \mathrm{~mol}^{-1}$, but up to 505 water molecules per IL ion pair could be stabilised to some degree. The desorption mechanisms and the reasons for these interactions are discussed.

\section{Introduction}

Molecular interactions between small solute molecules and ionic liquids (ILs) are of interest for academic reasons, to understand how materials dissolve in ionic liquids, and for industrial reasons, where ILs may be used to capture gases in the presence of contaminant gases. Average interactions between solute and 
solvent can be measured using solubility studies and Henry's law constants at different temperatures, and from enthalpies of mixing. However, these only give an average interaction whereas within an ionic liquid there will be ionic and non-ionic domains each capable of interacting over a range of energies with a dissolved solute. To gain a better understanding of the range of interactions involved between ionic liquids and small molecules, temperature programmed desorption (TPD) can be used, as a range of interactions will give a range of activation energies. Liquid ILs at room temperature and under the vacuum conditions necessary for TPD are unable to absorb small molecules, so to carry out TPD the temperature of the experiment must be lowered to $\approx 100 \mathrm{~K}$, and the components are intimately mixed on an unreactive substrate so that they can interact in all possible ways. This leads to two possibilities. Firstly, the IL solvent forms a porous solid structure with solute within the pores, or secondly the solvent becomes dispersed throughout a solid solute. Both provide a direct view of the range of solute-solvent interactions that must exist within the liquid at room temperature.

In this paper we investigate the interactions of three small molecules, acetone, sulfur dioxide and water with the ionic liquid 1-octyl-3-methylimidazolium tetrafluoroborate, [OMIM][BF4], using temperature programmed desorption with line of sight mass spectrometry (LOSMS) detection. [OMIM][BF 4 , Fig. 1A, was chosen as the imidazolium family of ionic liquids show solubility and selectivity for a range of gases and the combination of the long octyl chain attached to the imidazolium cation and the small $\left[\mathrm{BF}_{4}\right]^{-}$ anion, means that ionic and hydrocarbon regions are expected within the bulk structure. Acetone, $\mathrm{SO}_{2}$ and water were chosen as they are all small polar molecules, with $\mathrm{SO}_{2}$ of interest as a pollutant which could be captured using ILs. Multilayer quantities of the IL and the vapours were deposited onto a substrate at $90 \mathrm{~K}$ to study the interactions between the two. For the acetone work they were deposited sequentially, allowing each to form its own structure at $90 \mathrm{~K}$, with diffusion of acetone and movement within the IL structure occurring during the subsequent TPD run. For $\mathrm{SO}_{2}$ and water, the IL and the vapours were co-adsorbed simultaneously. In this case the initial structure at $90 \mathrm{~K}$ was an intimate mixture of the two materials, with neither the IL nor the adsorbate having formed a separate layer with a separate structure. This led to a difference in behaviour during subsequent TPD compared to the acetone case. We find that all three molecules can be stabilised by interaction with the ionic parts of $[\mathrm{OMIM}]\left[\mathrm{BF}_{4}\right]$, the interaction energy going as high as $1.6 \times$ the activation energy for desorption of acetone and $\mathrm{SO}_{2}$. For water the situation is complicated by a phase change. The number of molecules stabilised per ion pair of [OMIM] $\left[\mathrm{BF}_{4}\right]$ are 1.1 for acetone, 1.9 for $\mathrm{SO}_{2}$ and $>68$ for water. We also find destabilisation by interaction with the octyl chain parts of [OMIM] $\left[\mathrm{BF}_{4}\right]$.

$[\mathrm{OMIM}]\left[\mathrm{BF}_{4}\right]$ is an ionic liquid (IL) composed of the cation $[\mathrm{OMIM}]^{+}$and the anion $\left[\mathrm{BF}_{4}\right]^{-}$. It is a liquid at room temperature with a glass transition temperature of $190 \mathrm{~K}^{1}$. It does not evaporate in vacuum at 
room temperature due to its very low vapour pressure, but can be thermally evaporated to a vapour consisting of neutral ion pairs ${ }^{2}$. Acetone is a polar compound with a dipole moment of $2.91 \mathrm{D}$ and strong hydrogen bonding acceptor character. It has been studied previously interacting with the related IL $[\mathrm{EMIM}]\left[\mathrm{Tf}_{2} \mathrm{~N}\right]^{\mathrm{a}}$ at $100 \mathrm{~K}$ on a clean $\mathrm{Au}(111)$ surface $^{3}$. Acetone was stabilised by a monolayer of the IL snow (a porous structure formed by deposition at low temperature) adsorbed on top of the acetone, with an activation energy for desorption of $43 \mathrm{~kJ} \mathrm{~mol}^{-1}$ (clean) $\rightarrow 55 \mathrm{~kJ} \mathrm{~mol}^{-1}(\theta=1)$. For multilayers of IL, the amount of stabilised acetone approximately doubled consistent with the acetone residing in an ionic underlayer at the solid IL/vacuum interface. Dielectric spectroscopy has been used with mixtures of acetone and another closely related $\mathrm{IL},[\mathrm{BMIM}]\left[\mathrm{BF}_{4}\right]^{\mathrm{b}}$, which showed the acetone interacting primarily with the cation ${ }^{4}$. The enthalpy of mixing of acetone and $[\mathrm{BMIM}]\left[\mathrm{BF}_{4}\right]$ at infinite dilution is $-9.95(4) \mathrm{kJ}$ mol $^{-1}$ (exothermic). Computations ${ }^{5}$ have been carried out for acetone interacting with another closely related IL, $[\mathrm{MMIM}]\left[\mathrm{PF}_{6}\right]^{\mathrm{c}}$ which found that the oxygen of the carbonyl group interacts with the hydrogen in the 2 position on the imidazolium ring, Fig.1A, and a hydrogen from a methyl group to form a 6membered ring with a binding energy of $65 \mathrm{~kJ} \mathrm{~mol}^{-1}$. They also found that the acetone competed with the $\left[\mathrm{PF}_{6}\right]^{-}$ion for this position in the complex. Recently the interaction of [BMIM] $\left[\mathrm{BF}_{4}\right]$ with acetone on a quartz crystal microbalance has been used as the sensor for detecting acetone in human breath ${ }^{6}$.

$\mathrm{SO}_{2}$ is a bent, polar molecule having a dipole moment of $1.62 \mathrm{D}$. [BMIM][BF 4 , which has a shorter alkyl chain that $[\mathrm{OMIM}]\left[\mathrm{BF}_{4}\right]$, has been studied for its absorption of $\mathrm{SO}_{2}$ and found to have a high capacity ${ }^{7}$, being able to absorb an $\mathrm{SO}_{2}$ mole fraction of 0.56 at $293.15 \mathrm{~K}^{8}$. Monte Carlo simulations of $\mathrm{SO}_{2}$ with $[\mathrm{BMIM}]\left[\mathrm{BF}_{4}\right]{ }^{9}$ show strong interaction between the oxygen and the hydrogen in the 2 position of the imidazolium, with other favoured sites being oxygen interactions with the hydrogen in the 4 position and the hydrogen in the second $\mathrm{CH}_{2}$ group along the butyl chain. The sulfur interacts strongly with the $\left[\mathrm{BF}_{4}\right]^{-}$, as might be expected from the dipole on the $\mathrm{SO}_{2}$ molecule. Similarly to acetone, both the $\mathrm{SO}_{2}$ absorbate and the $\left[\mathrm{BF}_{4}\right]^{-}$cation favour bonding to hydrogen at the 2 position of the imidazolium.

Water is a polar molecule with a dipole moment of $1.85 \mathrm{D}$ and strong hydrogen bonding donor and acceptor capabilities. The enthalpy of mixing of water and [BMIM] $\left[\mathrm{BF}_{4}\right]$ at infinite dilution ${ }^{10}$ is $16.64(6)$ $\mathrm{kJ} \mathrm{mol}^{-1}$ (endothermic). Temperature dependent absorption studies of Henry's constants for water in $[\mathrm{OMIM}][\mathrm{BF} 4]^{11}$ gave an enthalpy of absorption of 34(5) $\mathrm{kJ} \mathrm{mol}^{-1}$. Experimental studies of water adsorption onto bulk liquid [OMIM] $\left[\mathrm{BF}_{4}\right]$ at $\approx 200 \mathrm{~K}$ using XPS ${ }^{12}$ indicated an activation energy for desorption from an ionic underlayer of about $74 \mathrm{~kJ} \mathrm{~mol}^{-1}$. Sticking probability measurements of water on

\footnotetext{
a $[\mathrm{EMIM}]\left[\mathrm{Tf}_{2} \mathrm{~N}\right]$ is 1-ethyl-3-methylimidazolium bis[(trifluoromethyl)sulfonyl]imide.

$\mathrm{b}$ [BMIM][BF4] is 1-butyl-3-methylimidazolium tetrafluoroborate.

c [MMIM][PF6] is 1-methyl-3-methylimidazolium hexafluorophophate.
} 
$[\mathrm{OMIM}]\left[\mathrm{BF}_{4}\right]^{13}$ showed that it physisorbed to the outmost octyl chain covered surface with a binding energy of $41 \mathrm{~kJ} \mathrm{~mol}^{-1}$ with activated adsorption $\left(17 \mathrm{~kJ} \mathrm{~mol}^{-1}\right)$ for the penetration of water through the octyl chain barrier to the ionic underlayer. This implies that the bonding of water within the ionic underlayer in the liquid IL was $\approx 59 \mathrm{~kJ} \mathrm{~mol}^{-1}$.
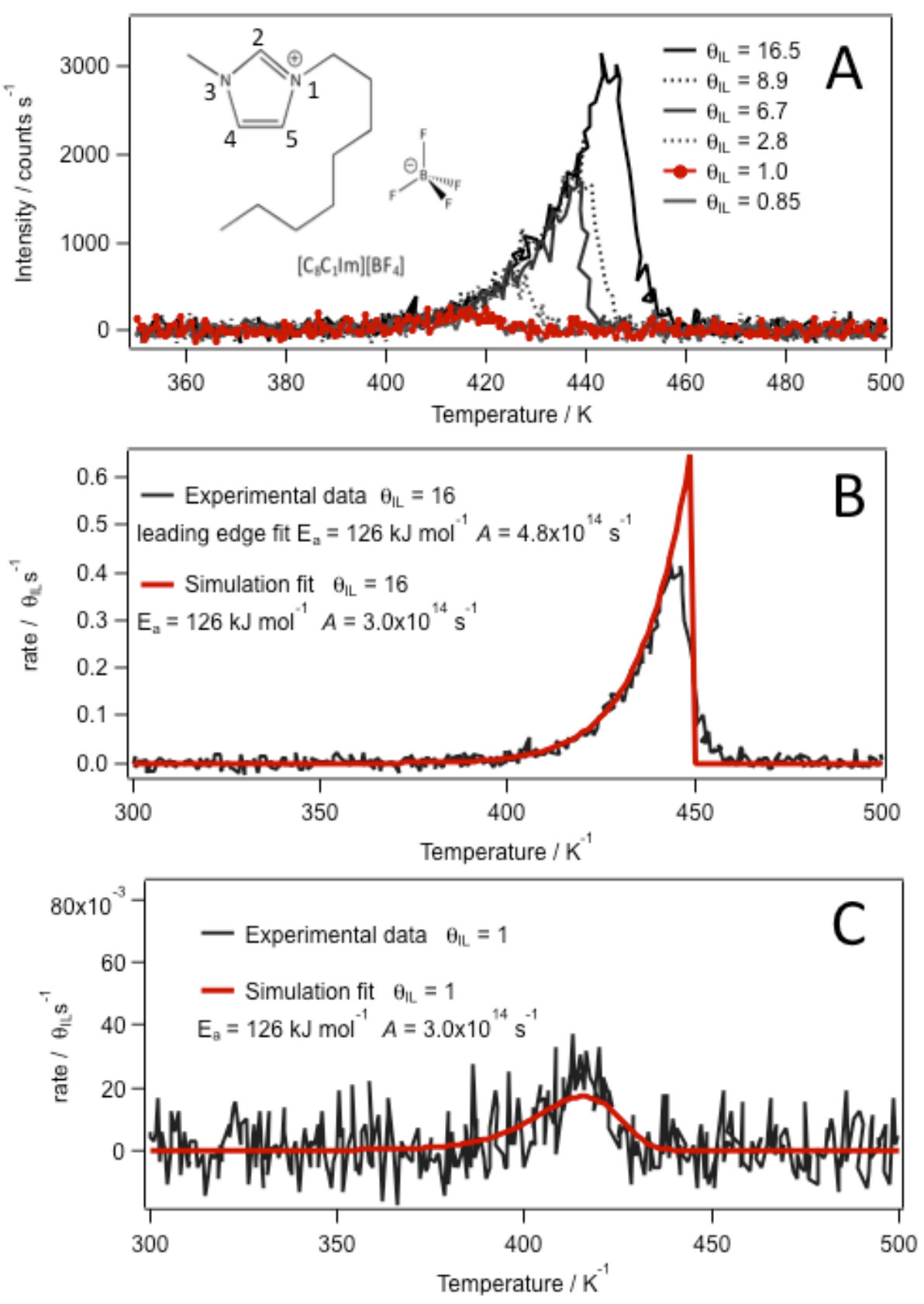

Figure 1. TPD scans for [OMIM] $\left[\mathrm{BF}_{4}\right]$ on CCAu. A, for increasing values of $\theta_{I L}$, inset shows the structure of 1-octyl-3-methylimidazolium tetrafluoroborate, [OMIM][BF $]$. B, $\theta_{I L}=16$ fitted with a zero order simulated curve. C, $\theta_{I L}=1$ fitted with a first order curve. $A=3.0 \times 10^{14} \mathrm{~s}^{-1}$ and $E_{a}=126 \mathrm{~kJ} \mathrm{~mol}^{-1}$ for both simulations. 


\section{Experimental}

The UHV chamber which had a base pressure of $5 \times 10^{-8} \mathrm{~Pa}$, has been described before ${ }^{14-19}$. Briefly, the LOSMS comprised a liquid nitrogen cooled differential pump containing a Hiden RC511 quadrupole mass spectrometer (range $m / z=0.4-510$ ) operated in pulse counting mode with an ionisation energy of $70 \mathrm{eV}$ and an ionisation current of $1 \mathrm{~mA}$. The line of sight defining apertures were $3 \mathrm{~mm}$ and $6 \mathrm{~mm}$ diameter located $110 \mathrm{~mm}$ and $170 \mathrm{~mm}$ from the sample, forming an $8 \mathrm{~mm}$ focal spot on the sample surface. The sample was a $\mathrm{Au}(111)$ crystal of $10 \mathrm{~mm}$ diameter, ensuring that only signal from the sample was detected. The sample could be heated and cooled in the range 90 - $700 \mathrm{~K}$. A type K thermocouple attached to the copper mounting plate adjacent to the sample was used for sample temperature measurement. As the interaction of the adlayer with the sample is not of interest here, the $\mathrm{Au}(111)$ surface was prepared by simply heating to $680 \mathrm{~K}$ to desorb organic residues from the surface. This formed a reproducible, though uncharacterised, layer of carbonaceous material on the Au(111) surface which will be referred to as carbon covered $\mathrm{Au}(\mathrm{CCAu})$.

The $[\mathrm{OMIM}]\left[\mathrm{BF}_{4}\right]$ was synthesised at Nottingham and deposited onto the CCAu surface using a homebuilt evaporator, which was attached to the vacuum chamber by a gate valve and separately pumped. The evaporator comprised a copper tube ( $15 \mathrm{~mm}$ diameter) divided by a internal copper partition such that one half contained a $50 \mathrm{~W}, 12 \mathrm{~V}$ quartz/halogen light bulb heater, while the other half contained a glass vial containing about $1 \mathrm{~cm}^{3}$ of the IL. A type $\mathrm{K}$ thermocouple was used to monitor the temperature of the copper tube. The IL vapour emanating from the vial was collimated into a molecular beam using a liquid nitrogen cooled baffle with a $10 \mathrm{~mm}$ aperture located $100 \mathrm{~mm}$ from the vial, the beam being turned on/off by simply opening/closing the gate valve. The evaporator was operated at $673 \mathrm{~K}$ for deposition experiments (duration of 5-10 mins) but otherwise held at $450 \mathrm{~K}$ to keep it degassed. When $[\mathrm{OMIM}]\left[\mathrm{BF}_{4}\right]$ was deposited on the CCAu at room temperature, it formed a liquid adlayer. On cooling this liquid layer to $90 \mathrm{~K}$, it froze to a glass (glass transition temperature of [OMIM][BF 4 is $192 \mathrm{~K}^{1}$ ). When IL vapour (which comprises ion pairs) was deposited onto the CCAu at $90 \mathrm{~K}$, the ion pairs stick where they land, forming a porous structure we will refer to as IL snow. Acetone, water and $\mathrm{SO}_{2}$ were dosed into the chamber via a leak valve from a separately pumped gas line, the pressure being measured with an ion gauge. The purity of all three was checked using the mass spectrometer in non line of sight mode (i.e. without liquid nitrogen cryo-pumping).

Temperature programmed desorption was carried out by heating the sample at $0.5 \mathrm{~K} \mathrm{~s}^{-1}$ and recording the total pressure, the temperature and appropriate ion intensities from the adsorbates using the LOSMS. During TPD the chamber pressure due to desorption of adsorbate from surfaces other than the CCAu sample can become large enough $\left(\approx 10^{-7} \mathrm{mbar}\right)$ that the vapour can reflect from the sample surface into the LOSMS, thus giving a small spurious signal. This can be removed by a background pressure 
subtraction method, where the total pressure curve is subtracted from the ion intensity curve of the adsorbate after suitable intensity calibration using a high temperature reflection feature. The method is described in ref 20,21 .

TPD can be described using the Polyanyi-Wigner equation

$$
-\frac{d \theta}{d t}=A \theta^{n} \exp \left(-\frac{E_{a}}{R T}\right)
$$

where $\theta$ is the coverage, $(\theta=1$ being a saturation layer $), t$ is time, $A$ the pre-exponential factor, $n$ the order of reaction, $E_{a}$ the activation energy for desorption, $T$ the temperature and $\mathrm{R}$ the universal gas constant. For simple multilayer desorption where $\theta>1$, the order is expected to be zero as each layer has the same surface area and the same bonding to the layer below. This gives a common leading edge for $d \theta / d t$ versus $T$ for increasing initial coverages, followed by a rapid drop as the surface coverage is exhausted. A leading edge analysis can be carried out on this zero order data by plotting $\ln (d \theta / d t)$ versus $1 / T$ which has a gradient of $E_{a} / \mathrm{R}$ and an intercept of $A$. Desorption simulations were carried out using the Polyanyi-Wigner equation where the rate of desorption was calculated for a short time increment at temperature $T$, followed by decrementing the surface coverage appropriately and incrementing the time and temperature for a new iteration, until desorption was complete. Such simulations, where $A, n$ and $E_{a}$ are fitting variables, can be matched to the experimental behaviour.

\section{Results}

\subsection{Desorption of $[\mathrm{OMIM}]\left[\mathrm{BF}_{4}\right]$}

To confirm that $[\mathrm{OMIM}]\left[\mathrm{BF}_{4}\right]$ was deposited on and desorbed from the CCAu surface without cracking, TPD curves were measured using different fragments of $[\mathrm{OMIM}]\left[\mathrm{BF}_{4}\right]$ and the relative intensities compared with the mass spectrum of the vapour from bulk IL. These are shown in the ESI, indicating that the IL did not crack. Here we use the intensity of the $m / z=195$ fragment due to the $[\mathrm{OMIM}]^{+}$cation as representative of the behaviour of the entire IL. TPD for different initial coverages, $\theta_{I L}$, were studied for $0.85 \leq \theta_{I L} \leq 16.5$, Fig. $1 \mathrm{~A}$. $\theta_{I L}=1$ was defined as the desorption peak which was clearly first order, prior to transitioning to a zero order peak shape with a common leading edge for higher (multilayer) coverages. A leading edge analysis of the zero order multilayer desorption peak gave an activation energy of $E_{a}=126(4) \mathrm{kJ} \mathrm{mol}^{-1}$ and a pre-exponential of $A=5 \times 10^{14(1)} \mathrm{s}^{-1}$. Simulations of the multilayer TPD curves using these values matched the experimental curves, Fig. 1B, as expected. The rather slow drop from maximum desorption rate for the zero order curves is probably due to the reaction order changing from zero order back to first order as the last layer of acetone desorbs. The single monolayer, $\theta_{I L}=1$, TPD, Fig. 1C was fitted with 1 st order kinetics using the same kinetic parameters as for the multilayers, indicating that the interaction between the CCAu and the IL is very similar to that between IL 
and IL. The similarity is consistent with the CCAu surface consisting of a thin layer of polymeric carbon containing material with some hydrocarbon chains at the surface. The van der Waals interactions between this surface and the octyl chains in $[\mathrm{OMIM}]^{+}$will be rather similar to the van der Waals interactions between the $[\mathrm{OMIM}]^{+}$species in multilayers of the IL. Also, due to the opposite sign image charges formed below the conducting gold surface by the ion charges above it in the adlayer, the Coulombic interactions in the monolayer are due to a double layer. Multilayer will have equivalent image charges further below the surface. The result is that from monolayer to multilayers the surface consists of an ionic adlayer and an image ionic layer, separated by a thin carbonaceous film that interacts very similarly to IL/IL van der Waals interactions. Hence there is no measurable difference between monolayer and multilayer interactions.

The multilayer [OMIM] $\left[\mathrm{BF}_{4}\right]$ desorption parameters found here $\left(E_{a}=126(4) \mathrm{kJ} \mathrm{mol}^{-1}, A=3 \times 10^{14(1)} \mathrm{s}^{-1}\right)$ were measured at an average desorption temperature of $425 \mathrm{~K}$, where as the previous bulk desorption parameter $^{14}\left(E_{a}=136(3) \mathrm{kJ} \mathrm{mol}^{-1}, A\right.$ not determined $)$ was measured at an average temperature of $520 \mathrm{~K}$. The activation energy for IL multilayers on CCAu is significantly smaller than the bulk value but this is not due to the difference in temperature, as $E_{a}$ would be expected to increase with decreasing temperature 14. The difference may be due to the small, finite thickness of the IL multilayers here (and their image charges) leading to a reduced Madelung potential for the ions and hence a smaller activation energy for desorption of the IL ion pairs ${ }^{18,22}$.

\subsection{Desorption of acetone}

\subsubsection{Acetone on CCAu}

Acetone TPD was monitored by its parent ion $\left[\left(\mathrm{CH}_{3}\right)_{2} \mathrm{CO}\right]^{+}(\mathrm{m} / z=58)$ and most intense fragment $[(\mathrm{CH} 3) \mathrm{CO}]^{+}(\mathrm{m} / z=43)$. Both behaved identically indicating that acetone absorbed and desorbed molecularly. The data was background pressure subtracted to produce signals due to desorption from the surface alone. 


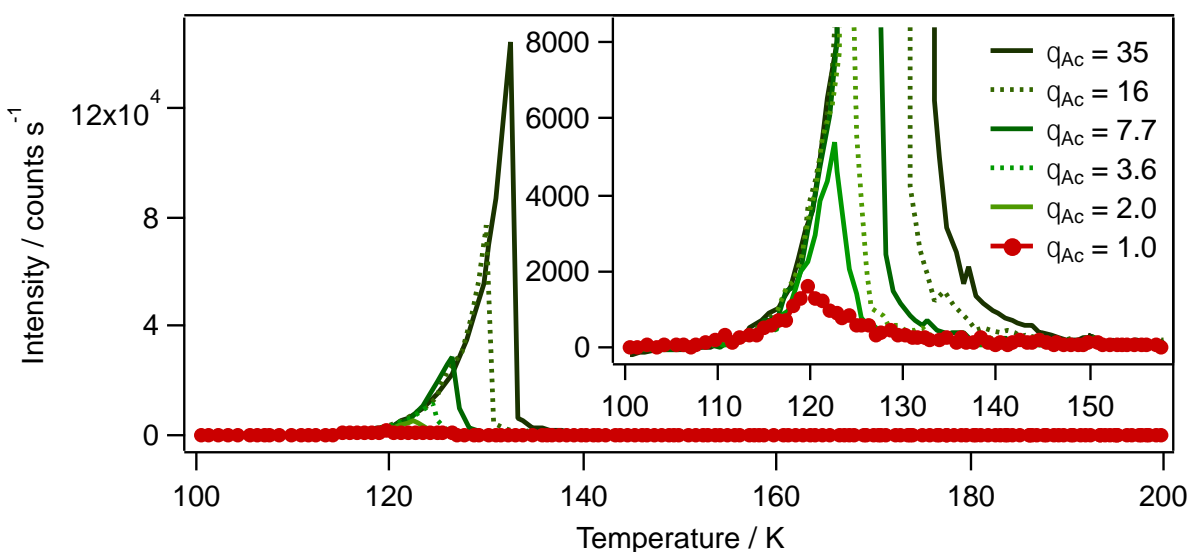

Figure 2. TPD scans of acetone on CCAu for increasing values of $\theta_{A c}$, using $m / z=58$. Inset shows expanded intensity scale.

Figure 2 shows a set of TPD curves obtained for pure acetone on CCAu for initial coverages $1.0 \leq \theta_{A c} \leq$ 35. $\theta_{A c}=1$ was defined where the zero order multilayer desorption shape became a first order desorption shape for the first layer. Leading edge analysis of the multilayer desorption peak gave $E_{a}=38(2) \mathrm{kJ} \mathrm{mol}^{-1}$ and a pre-exponential of $A=4 \times 10^{15(1)} \mathrm{s}^{-1}$. These values were used to match the zero order multilayer TPD curves and the first order monolayer TPD curve by simulation, see ESI. $E_{a}$ and $A$ are consistent with those found previously for multilayer desorption of acetone from $\mathrm{Au}(111)^{3}$

\subsubsection{Acetone on IL glass}

Acetone was adsorbed onto the IL glass at $100 \mathrm{~K}$ (formed by cooling the IL liquid layer from $300 \mathrm{~K}$ ) and TPD carried out. For multilayers the curves showed the same zero order shape as for adsorption on the CCAu surface, and gave the same $E_{a}$ and $A$ values by leading edge analysis. For the monoalyer a good fit was found using first order desorption with a linearly changing activation energy $E_{a}=38.5 \mathrm{~kJ} \mathrm{~mol}^{-1}$ $\left(\theta_{A c}=1\right) \rightarrow 37 \mathrm{~kJ} \mathrm{~mol}^{-1}\left(\theta_{A c}=0\right)$ and a pre-exponential of $A=1.5 \times 10^{16(1)}$, i.e. essentially the same as for adsorption on the CCAu surface. This is consistent with the IL glass being terminated by octyl chains, such that the IL glass and the CCAu are both, effectively hydrocarbon surfaces. These results are consistent with the IL glass being impermeable such that no acetone penetrated the surface.

\subsubsection{Acetone on IL snow}

Acetone coverages of $0.6 \leq \theta_{A c} \leq 25$ were deposited onto IL snow having a constant coverage of $\theta_{I L}=10$ at $\approx 90 \mathrm{~K}$. TPD scans were then taken on subsequent heating, Fig. 3A. At low coverage, $\theta_{A c}=0.6$, acetone desorption commences at about $130 \mathrm{~K}$ and continues up to $200 \mathrm{~K}$, indicating very substantial stabilisation of the acetone by the IL snow. For increasing acetone coverage the long, stabilised region from $140-200 \mathrm{~K}$ increases in intensity slightly. We attribute this stabilised acetone to adsorption within 
the pores of the IL snow which places acetone in close proximity to the ionic parts of the IL (including ions at the surface of the IL). For $\theta_{A c}=6.3$ or 6.4 a low temperature peak grows at $118-120 \mathrm{~K}$, which increases in intensity and moves to a slightly higher temperature for $\theta_{A c}=25$. This low temperature peak is due to multilayers of acetone, but lies at a substantially lower temperature than multilayers of pure acetone on CCAu. We attribute this to destabilised acetone within the pores of the IL snow. For the highest coverage $\left(\theta_{A c}=25\right)$ the destabilised actone peak has grown and become approximately zero order with at peak at $\approx 124 \mathrm{~K}$. A peak has also begun to grow at $\approx 135 \mathrm{~K}$ which corresponds to formation of multlayers of pure acetone as observed for multilayers on CCAu and the IL glass. We assume this $135 \mathrm{~K}$ peak is due to multilayer growth on the outside of the IL snow, such that the acetone bonding is the same as pure solid acetone. The activation energy of the low temperature part of the peak, using a leading edge analysis, was $36(2) \mathrm{kJ} \mathrm{mol}^{-1}$ with $\mathrm{A}=4 \times 10^{15(1)} \mathrm{s}^{-1}$, which is lower than the $38 \mathrm{~kJ} \mathrm{~mol}^{-1}$ for pure acetone on CCAu, indicating that the acetone has grown as a structure that is less stable within the pores of the IL snow. We suggest that this occurs in regions of the IL snow that are dominated by the octyl chains of the $[\mathrm{OMIM}]^{+}$ion.
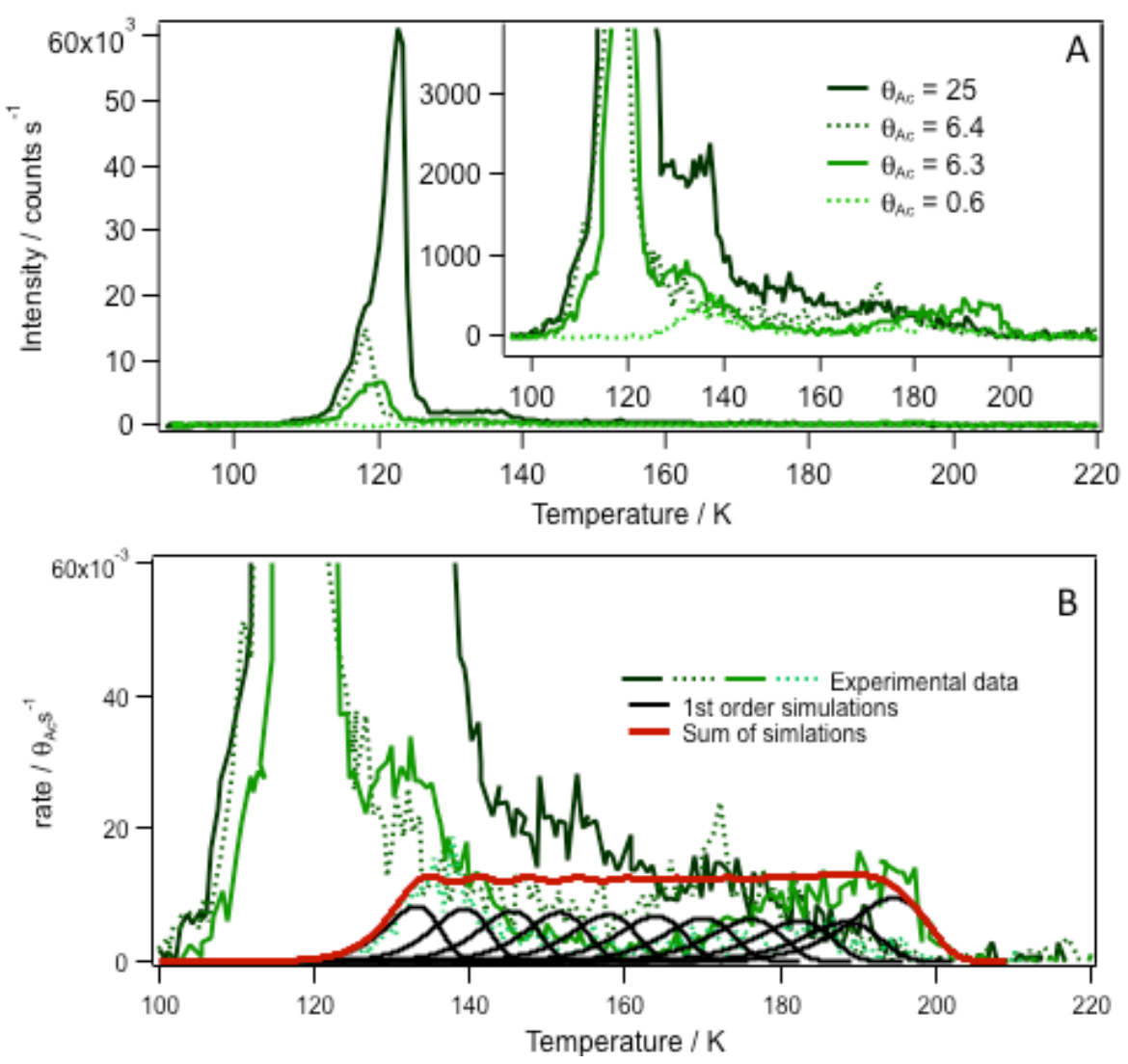

Figure 3. TPD scans of acetone on IL snow $\left(\theta_{I L}=10\right)$ for increasing values of $\theta_{A c}$, using $m / z=58$. A, four initial coverages of acetone $\left(0.6 \leq \theta_{A c} \leq 25\right)$, inset shows expanded intensity scale. $\mathrm{B}$, the scans from A fitted with a summation (solid line) of 11 first order desorption peaks (dotted lines) with activation energies of $40-62 \mathrm{~kJ} \mathrm{~mol}^{-1}$ in $2 \mathrm{~kJ} \mathrm{~mol}^{-1}$ steps. 
The desorption data from 130 - $200 \mathrm{~K}$ could be modeled approximately using a summation of 11 first order desorption curves with activation energies from $40-62 \mathrm{~kJ} \mathrm{~mol}^{-1}$ in $2 \mathrm{~kJ} \mathrm{~mol}^{-1}$ steps using $A=$ $4 \times 10^{15(1)} \mathrm{s}^{-1}$, see Fig. 3B. The fit aims to simulate a continuum of activation energies rather than simply 11 discrete adsorption sites. This simulation adequately duplicates the acetone TPD behaviour indicating that the acetone deposited on the surface of the IL snow has diffused into it and become stabilised over this range of interaction energies. The total amount of stabilised acetone accommodated in the simulation is $\theta_{A c, s t a b}=2.5$, i.e. $\theta_{A c, s t a b} / \theta_{I L}=0.25$ for acetone adsorbed directly through the IL snow surface. This is consistent with acetone penetrating some layers down into the IL snow $(\approx 5)$, but not through the entire 10 layers of IL.

\subsubsection{Acetone adsorption beneath IL snow}

To increase the possibility of acetone/IL snow interaction, acetone was absorbed first on CCAu, followed by adsorption of the IL at $\approx 90 \mathrm{~K}$ to form on over-layer of IL snow. In this way the acetone was forced to pass through the IL snow during TPD. Two types of experiment were carried out: different coverages of acetone were adsorbed beneath a constant coverage of IL, and an excess amount of acetone was adsorbed beneath different coverages of IL.
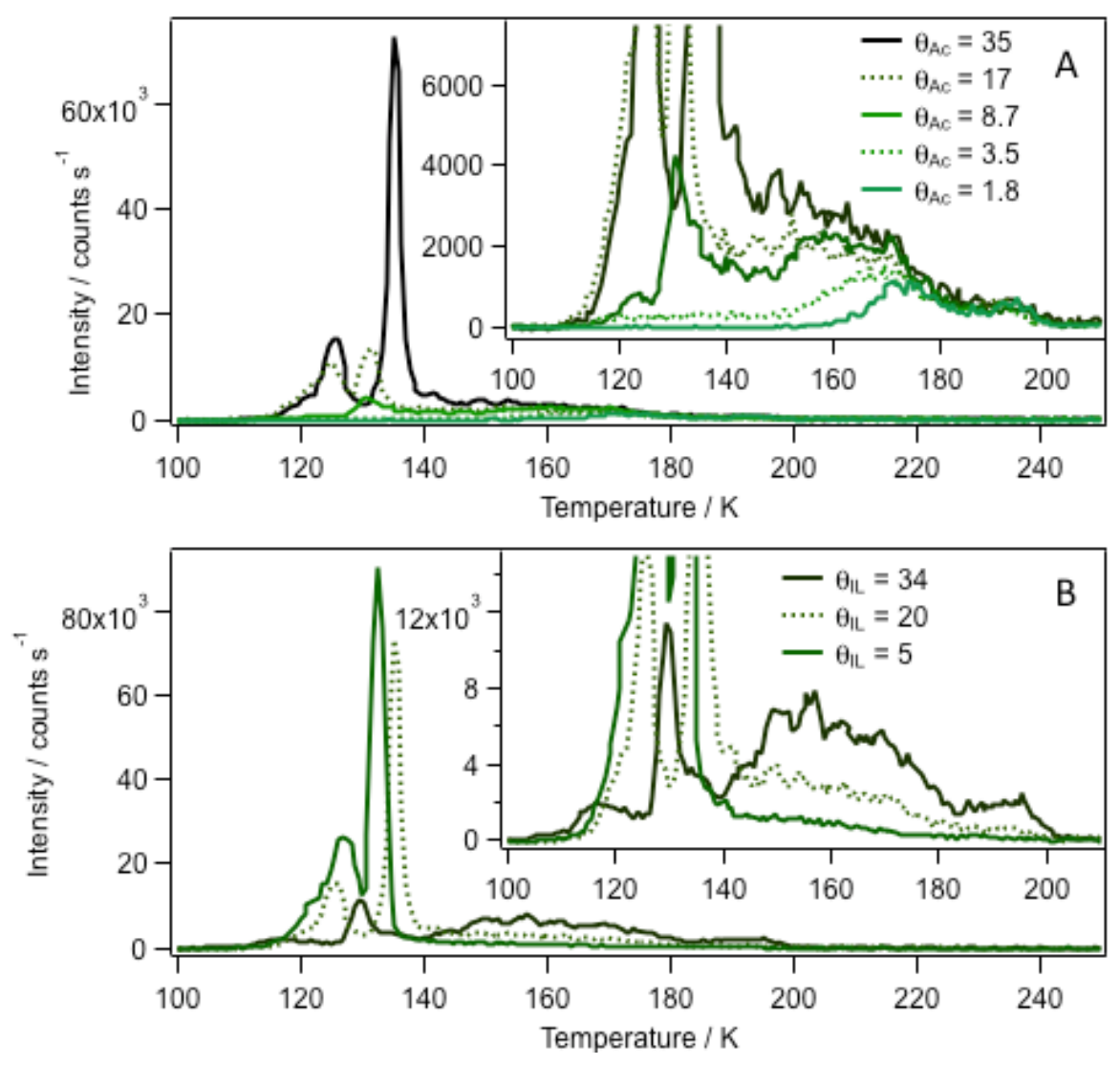
Figure 4. TPD scans of acetone beneath IL snow using $m / z=58$. A, five initial coverages of acetone (1.8 $\left.\leq \theta_{A c} \leq 35\right)$ adsorbed beneath a constant coverage of IL snow $\left(\theta_{I L}=20\right)$, inset shows expanded intensity scale. B, three initial coverages of IL, $\theta_{I L}=5,20,34$ adsorbed on top of a constant coverage of acetone, $\theta_{A c}=35$, inset shows expanded intensity scale.

Figure 4A shows TPD scans for acetone coverages of $1.8 \leq \theta_{A c} \leq 35$ adsorbed beneath IL snow of coverage $\theta_{I L}=20$. For temperatures $140-200 \mathrm{~K}$, low initial coverages of acetone fill the highest temperature desorption states, and then for increasing initial coverages the states are sequentially filled towards lower temperature, forming an envelope of desorption sites from $140-200 \mathrm{~K}$. For $\theta_{A c}=8.7$ the envelope of sites is almost full and a desorption peak appears at $130 \mathrm{~K}$. For $\theta_{A c}=17$ the envelope of sites fills only slightly more at $\approx 140 \mathrm{~K}$, the peak at $130 \mathrm{~K}$ grows in intensity and a new peak at $125 \mathrm{~K}$ starts to grow. For the highest initial coverage the $125 \mathrm{~K}$ peak grows a little more, the $130 \mathrm{~K}$ peak disappears and a large peak appears at $135 \mathrm{~K}$. The three peaks at 125,130 and $135 \mathrm{~K}$ are significantly narrower than would be expected for simple zero or first order desorption peaks. The most intense of the three, at $135 \mathrm{~K}$, is similar to the desorption of pure acetone from CCAu and probably represents multilayers of acetone on the substrate surface desorbing through large pores or cracks in the IL snow. The other two peaks at lower temperature correspond to acetone that has moved into the IL snow and is destabilised by its interactions with the IL, such that on heating, it is desorbed at lower temperatures than pure acetone. The loss of the peak at $130 \mathrm{~K}$ suggests that this destabilised state drains acetone back to the more stable pure acetone state at $135 \mathrm{~K}$ for the higher initial coverage. Why the even less stable $125 \mathrm{~K}$ state does not also disappear, is not clear. All three states, 125, 130 and $135 \mathrm{~K}$ are at a higher temperature than the lowest temperature state for acetone adsorbed on top of IL snow (118-120 K). This is consistent with pores within the IL being somewhat more bonding than the hydrocarbon covered surface of the IL glass.

In the second set of experiments IL coverages $\theta_{I L}=5,20$ and 35 were deposited onto a fixed coverage of acetone, $\theta_{A c}=35$, at $\approx 100 \mathrm{~K}$, see Fig. 4B. Again there is an envelope of stabilised states for $T>140 \mathrm{~K}$ which increase in intensity as the IL coverage increases. The highest temperature state, for $T>180 \mathrm{~K}$, seems particularly intense for the highest coverage of $\theta_{I L}=34$. For $T<140 \mathrm{~K}$ there are two clear, intense peaks for the lowest IL coverage, $\theta_{I L}=5$, which correspond to multilayers of destabilised acetone, the 125 $\mathrm{K}$ peak, and multilayers of pure acetone, the $135 \mathrm{~K}$ peak (note that the acetone was in excess for this IL coverage). For the next highest coverage of IL, $\theta_{I L}=20$, both peaks reduced in intensity with the higher temperature peak moving to higher temperature, and the lower one to lower temperature. The reduction in intensity is consistent with more acetone being stabilised in the $T>140 \mathrm{~K}$ states but the shifts in temperature are not readily explainable. For the highest IL coverage, $\theta_{I L}=34$, virtually all the acetone is accommodated in the stabilised states for $T>140$, and the small amount of destabilised acetone occupies 
a small single peak at $130 \mathrm{~K}$. The appearance of this peak coincides with the appearance of the high temperature state at $T>180 \mathrm{~K}$, suggesting some structural change has occurred in the IL for $20<\theta_{I L} \leq$ 35.

The stabilised region from 140 - $200 \mathrm{~K}$ for all three IL coverage was fitted using the sum of 7 first order desorption curves with activation energies from $45-57 \mathrm{~kJ} \mathrm{~mol}^{-1}$ in increments of $2 \mathrm{~kJ} \mathrm{~mol}^{-1}$, region A, and an eighth with an activation energy of $61 \mathrm{~kJ} \mathrm{~mol}^{-1}$, region B, Fig. 5B. A pre-exponential of $4.3 \times 10^{15}$ $\mathrm{s}^{-1}$ was used and the initial coverages were adjusted to obtain a good match to the overall shape of the experiment. Fig. 5A shows the fit for $\theta_{I L}=5$, while the fits to the other two coverages are shown in the ESI. We assume that the adsorbed acetone layer within the IL pores is one molecule thick, which justifies the use of first order desorption kinetics. As the pore surface area greatly exceeds the geometrical surface area of the sample for which $\theta_{A c}=1$ is defined, values of $\theta_{A c}>1$ in our simulations are expected.
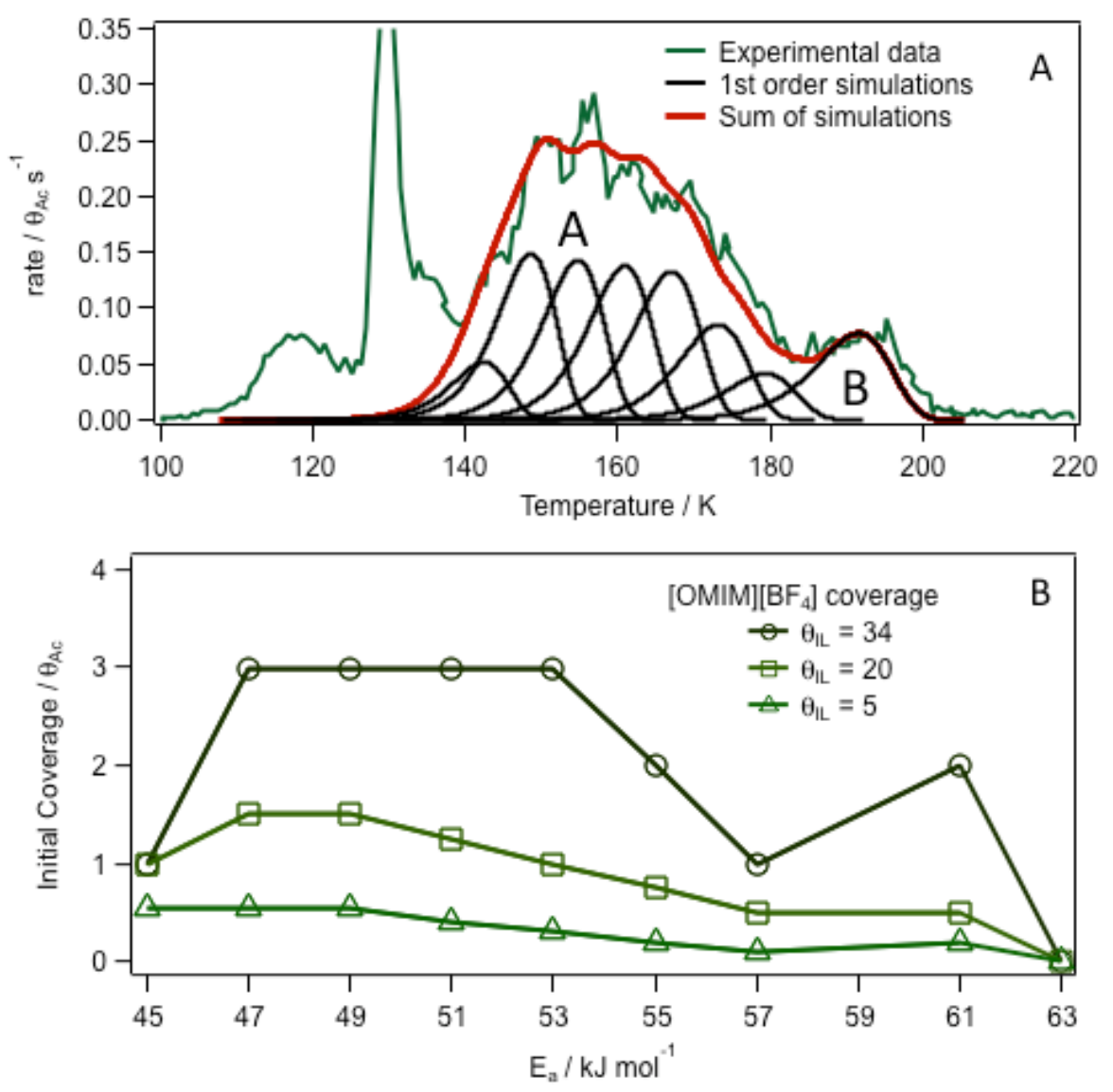

Figure 5. A, TPD scan of acetone $\left(\theta_{A c}=35\right)$ beneath IL snow $\left(\theta_{I L}=34\right)$ using $m / z=58$, fitted with the sum of eight first order simulation curves. Regions A and B are shown. B, Simulation initial coverages at each activation energy versus activation energy for fitting the sum of first order desorption curve to $140 \mathrm{~K}$ $<T<200 \mathrm{~K}$ for $\theta_{I L}=5,20$, and 34, on top of a constant coverage of acetone, $\theta_{A c}=35$. 
Figure 5B shows the initial coverages for each first order desorption state used to simulate the desorption curves for $T>140 \mathrm{~K}$ for all three initial coverages of IL. The overall quantity of stabilised acetone, $\theta_{A c, s t a b}$ rises linearly with IL coverage, with $\theta_{A c, s t a b} / \theta_{I L} \approx 0.5$ i.e. about half a monolayer of acetone is stabilised by each monolayer of IL. This is higher than the $\theta_{A c, s t a b} / \theta_{I L} \approx 0.25$ found for adsorption of acetone on top of IL snow, indicating that the acetone was able to access more sites within the IL snow when moving from below it towards vacuum. It is also clear from Fig. 5B that the single highest temperature state at $61 \mathrm{~kJ} \mathrm{~mol}^{-1}$ undergoes a large increase in relative intensity for the highest coverage of IL, suggesting that this particularly stable state becomes more abundant for $\theta_{I L}>20$.

\subsubsection{Discussion of acetone stabilisation}

Acetone adsorption on the IL glass at $90 \mathrm{~K}$ showed the same multilayer desorption behaviour as for adsorption on the CCAu surface. This is consistent with the acetone being unable to penetrate either surface and hence it simply forms multilayers of pure, solid acetone. The monolayer of acetone on the IL glass did show a slightly lower activation energy consistent with adsorption on a surface in which the acetone-IL adsorption bonding is less than acetone-acetone bonding. This is consistent with the IL glass having a surface structure similar to the IL liquid from which it was formed, consisting of octyl chains at the surface with the ionic moieties subsurface, such that the acetone can only van der Waals bond with the alkyl chains.

For acetone lying below the IL snow we propose the following model. The acetone was deposited onto the CCAu surface at $90 \mathrm{~K}$ which was $\approx 0.7$ of the acetone desorption temperature, indicative of reasonable mobility at the adsorption temperature. The acetone therefore probably had sufficient surface mobility to grow as a reasonably compact solid. The IL was deposited on top of the acetone, also at $90 \mathrm{~K}$, which is very much lower than the glass transition temperature of [OMIM][BF $4\left(192 \mathrm{~K}^{1}\right)$ and only 0.2 of the IL desorption temperature. We therefore assume that during adsorption the IL ion pairs in the gas phase stick where they land, and are unable to diffuse to form a compact structure. The IL is therefore an open network of ion pairs containing molecular sized pores where the cationic and anionic moieties as well as the octyl chains on the cations are exposed to vacuum via the pores, Fig. 6A. The stabilised acetone we broadly associate with acetone interacting with the charged, ionic parts of the IL. The destabilised acetone can be due to acetone interacting with the octyl chains on the cations or possibly a disordered form of adsorbed acetone with a lower activation energy for desorption.

Figure 6A shows a schematic of the starting arrangement of a fairly compact acetone layer surmounted by a disordered IL snow containing pores, where the pores can range in structure from those lined solely with octyl chains through to those lined solely with ions. This will give pores that can stabilise acetone to 
different degrees, and pores that will destabilise acetone to different degrees, depending on the mix of charged and alkyl species. As the temperature rises to $\approx 120 \mathrm{~K}$ the acetone becomes sufficiently mobile that it can diffuse below and into the overlying IL snow. For an excess of acetone, all the pores are filled, Fig. 6B with some pure acetone still remaining outside of the IL. On heating to $140 \mathrm{~K}$ acetone within the octyl chain lined pores has desorbed, as has any excess pure acetone, leaving the stabilised acetone within the ion lined pores, Fig. 6C. We speculate that the octyl chain lined pores may have collapsed at this stage which had the effect of squeezing out acetone as the destabilised peak at $125 \mathrm{~K}$, with the other slightly stabilised peak at $\approx 135 \mathrm{~K}$ being due to acetone being eliminated from slightly less destabilised pores. The sharp peaks seen for these destabilising pores suggests that they are relatively uniform in nature. From 140 - $180 \mathrm{~K}$ acetone desorbs from a continuum of stabilised sites with activation energies of $45-61 \mathrm{~kJ} \mathrm{~mol}^{-1}$ from pores with different geometries and densities of ions on the pore surfaces. For the highest IL coverage of $\theta_{I L}=34$, there was a large increase in the number of states at $61 \mathrm{~kJ} \mathrm{~mol}^{-1}$ which we think may be due to the formation of an ionic underlayer within the solid IL consisting of a layer of anions and cations lying below an outermost layer of octyl chains, Fig. 6D. Such a layer would allow maximum interaction between ions and acetone, causing the highest stabilisation value as well as an increased number of absorption sites. It is also possible that the ionic liquid undergoes a more general structural change at about $180 \mathrm{~K}$, such as dissociation of the ion pairs to separate ions ${ }^{23}$, which produces the stabilised state of $61 \mathrm{~kJ} \mathrm{~mol}^{-1}$ throughout the thickness of the IL. However, no such states were observed for lower IL coverages, suggesting that any general change had minimal effect on the stabilised acetone in the pores. We slightly favour the ionic underlayer model, but cannot rule out a general structural change. For $190 \mathrm{~K}$ and hotter, the remaining acetone in the $61 \mathrm{~kJ} \mathrm{~mol}^{-1}$ state desorbs, leaving just the ionic liquid on the surface. 


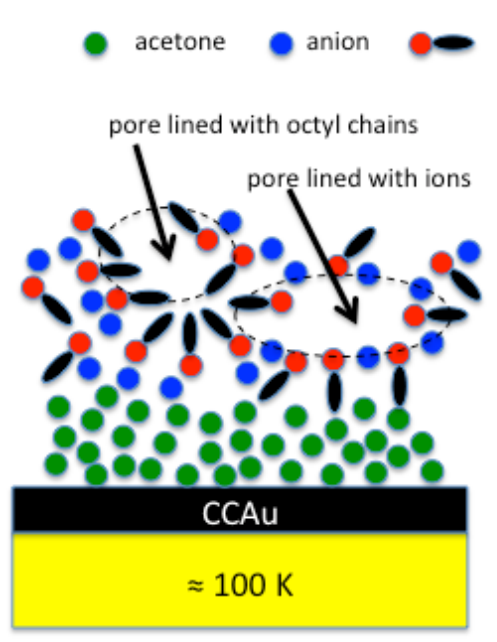

A

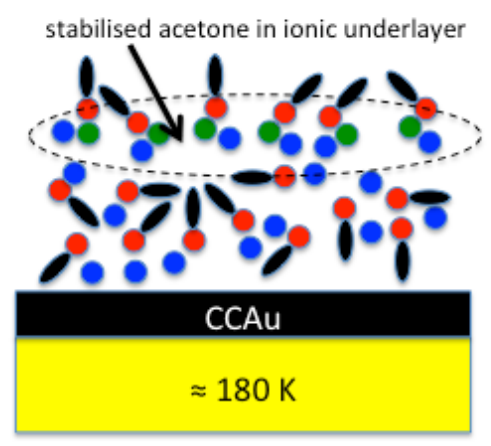

D

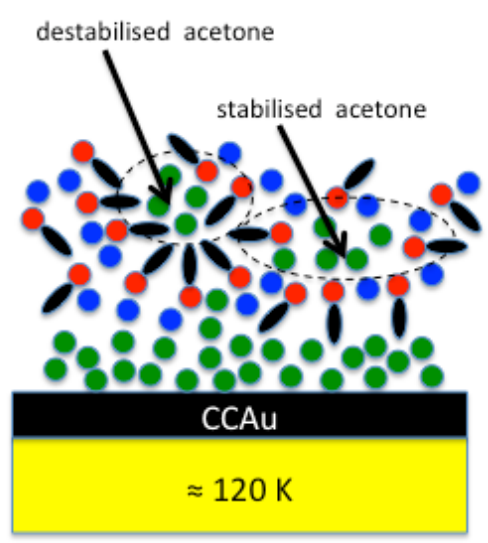

B

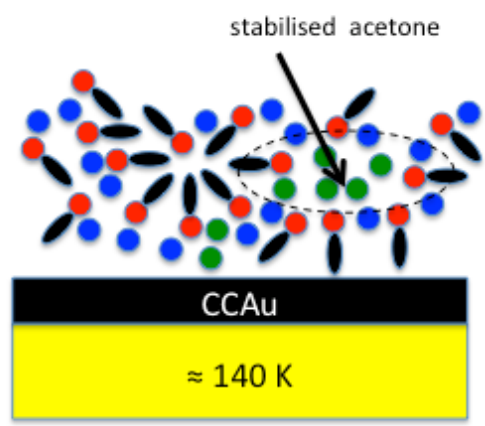

C

Figure 6. Schematic illustration of desorption of acetone from beneath an IL snow overlayer. A, as deposited at $\approx 100 \mathrm{~K}$. B, after heating to $120 \mathrm{~K}$ so that acetone diffuses into pores lined with octyl chains (destabilised acetone) and pores lined with ions (stabilised acetone). C, after heating to $140 \mathrm{~K}$ so that the destabilised acetone has desorbed but the stabilised acetone is still absorbed near to the ions. D, after heating to $180 \mathrm{~K}$ where an ionic underlayer has formed containing strongly stabilised acetone within it.

It was found that $\theta_{A c, s t a b} / \theta_{I L}=0.5$ for the maximum amount of acetone stabilised within the ionic liquid for $T>140 \mathrm{~K}$. Using the molar volumes, $V_{m}$, of acetone $\left(0.0733 \times 10^{-3} \mathrm{~m}^{3} \mathrm{~mol}^{-1}\right)$ and the IL $\left(0.255 \times 10^{-3}\right.$ $\left.\mathrm{m}^{3} \mathrm{~mol}^{-1}\right)$, the surface concentration of an average molecular monolayer is given by $\left(\mathrm{N}_{\mathrm{A}} / V_{m}\right)^{2 / 3}$, giving $4.07 \times 10^{18}$ molecules $\mathrm{m}^{-2}$ for $\theta_{A c}=1$ and $1.78 \times 10^{18}$ molecules $\mathrm{m}^{-2}$ for $\theta_{I L}=1$. Hence $\theta_{A c, s t a b} / \theta_{I L}=0.5$ corresponds to 1.1 acetone molecules per ion pair of the IL (or a mole fraction of $\approx 0.53$ ). The same calculation gives about 0.5 acetone molecules per ion pair for stabilised acetone formed from acetone adsorbed on top of the IL snow.

Neither the size, nor the size distribution of the pores in the IL snow have been determined. Given the mode of formation, ( 0.2 of the IL desorption temperature, where the ion pairs stick where they land) we expect pores and cavities of about the size as the ion pair $(\mathrm{nm})$ with not many pores of greater size. The 
ratio of approximately one acetone per IL ion pair for the maximum stabilised coverage shows the IL snow has virtually all the IL at internal surfaces, which is only consistent with a high surface area material with nm sized pores. This is supported by the smaller amount of acetone ( 0.5 molecules per IL ion pair) which could be stabilised when it had to first diffuse down into the IL snow from acetone adsorbed above the IL, nm sized channels being a significant barrier compared to easy desorption into the vacuum. We therefore suggest that the pores were nm in size and not large enough to allow solid acetone to condense within them.

\subsection{Desorption of $\mathrm{SO}_{2}$}

TPD of $\mathrm{SO}_{2}$ was monitored using $m / z=64\left(\mathrm{SO}_{2}{ }^{+}\right)$and $48\left(\mathrm{SO}^{+}\right)$. Both behaved identically indicating that no chemical reaction occurs between the surface and $\mathrm{SO}_{2}$. The $m / z=64$ data is presented below and it should be noted that as the IL has a fragment at $m / z=64$, the desorption of the IL was monitored by this fragment at elevated temperatures. Figure 7A shows TPD scans of pure $\mathrm{SO}_{2}$ from the CCAu surface for initial coverages of $\theta_{\mathrm{SO} 2}=1$ - 37. As for acetone and IL desorption described above, $\theta_{\mathrm{SO} 2}=1$ was defined as the highest coverage that exhibited a first order desorption profile. A leading edge analysis of the highest coverage scan gave $E_{a}=32(2) \mathrm{kJ} \mathrm{mol}^{-1}$ and a pre-exponential of $6 \times 10^{14(1)} \mathrm{s}^{-1}$ and simulated zero order TPD curves using these values fitted the experimental data very well. The monolayer coverage of $\mathrm{SO}_{2}$ was fitted with a first order curve with $E_{a}=32 \mathrm{~kJ} \mathrm{~mol}^{-1}$ and $A=1 \times 10^{15} \mathrm{~s}^{-1}$.

Two types of experiment were carried out, which differed from those carried out for acetone in that the $\mathrm{SO}_{2}$ and the IL were co-adsorbed to increase mixing to the highest possible degree. In the first, different amounts of $\mathrm{SO}_{2}$ were co-adsorbed with a constant amount of IL at $90 \mathrm{~K}$, followed by TPD. In the second, a constant excess amount of $\mathrm{SO}_{2}$ and different amounts of $\mathrm{IL}$ were co-adsorbed at $90 \mathrm{~K}$, followed by TPD.

Figure 7B shows increasing amounts of $\mathrm{SO}_{2}$ co-adsorbed with a fixed coverage of $\mathrm{IL}, \theta_{I L}=10$, at $90 \mathrm{~K}$. Relative to the desorption of pure $\mathrm{SO}_{2}$ there is a stablilised region from about $120 \mathrm{~K}-180 \mathrm{~K}$. For $\theta_{S O 2} \leq$ 20 the amount of $\mathrm{SO}_{2}$ in the stabilised region grows, as does the amount in a slightly destabilised region with a peak at $120 \mathrm{~K}$ which moves to lower temperature for increasing coverage. The high temperature states above $130 \mathrm{~K}$ become saturated at $\theta_{\mathrm{SO} 2}=47$. For $\theta_{\mathrm{SO} 2} \geq 25$ the low temperature peak grows in intensity and shifts to higher temperature, behaving rather like a zero order peak. However, for the highest coverage of $\theta_{\mathrm{SO} 2}=110$ this peak grows and broadens into an almost flat topped peak. This peak is partly stabilised relative to the pure $\mathrm{SO}_{2}$ but it shows no sign of turning into a zero order peak of pure $\mathrm{SO}_{2}$. 
Figure 7C shows TPD for increasing coverages of $\mathrm{IL}\left(\theta_{I L}=4.0,8.7\right.$ and 12) for a fixed amount of $\mathrm{SO}_{2}$ $\left(\theta_{\mathrm{SO}_{2}}=50 \pm 4\right)$. In the region 130 to $180 \mathrm{~K}$ the envelope of stabilised states increases as the IL coverage increases such that more $\mathrm{SO}_{2}$ is stabilised. At lower temperatures, a single peak is seen at $120 \mathrm{~K}$ which decreases in intensity as the IL coverage increases, consistent with more $\mathrm{SO}_{2}$ moving into stabilised states for $T>130 \mathrm{~K}$ as the IL coverage increases.
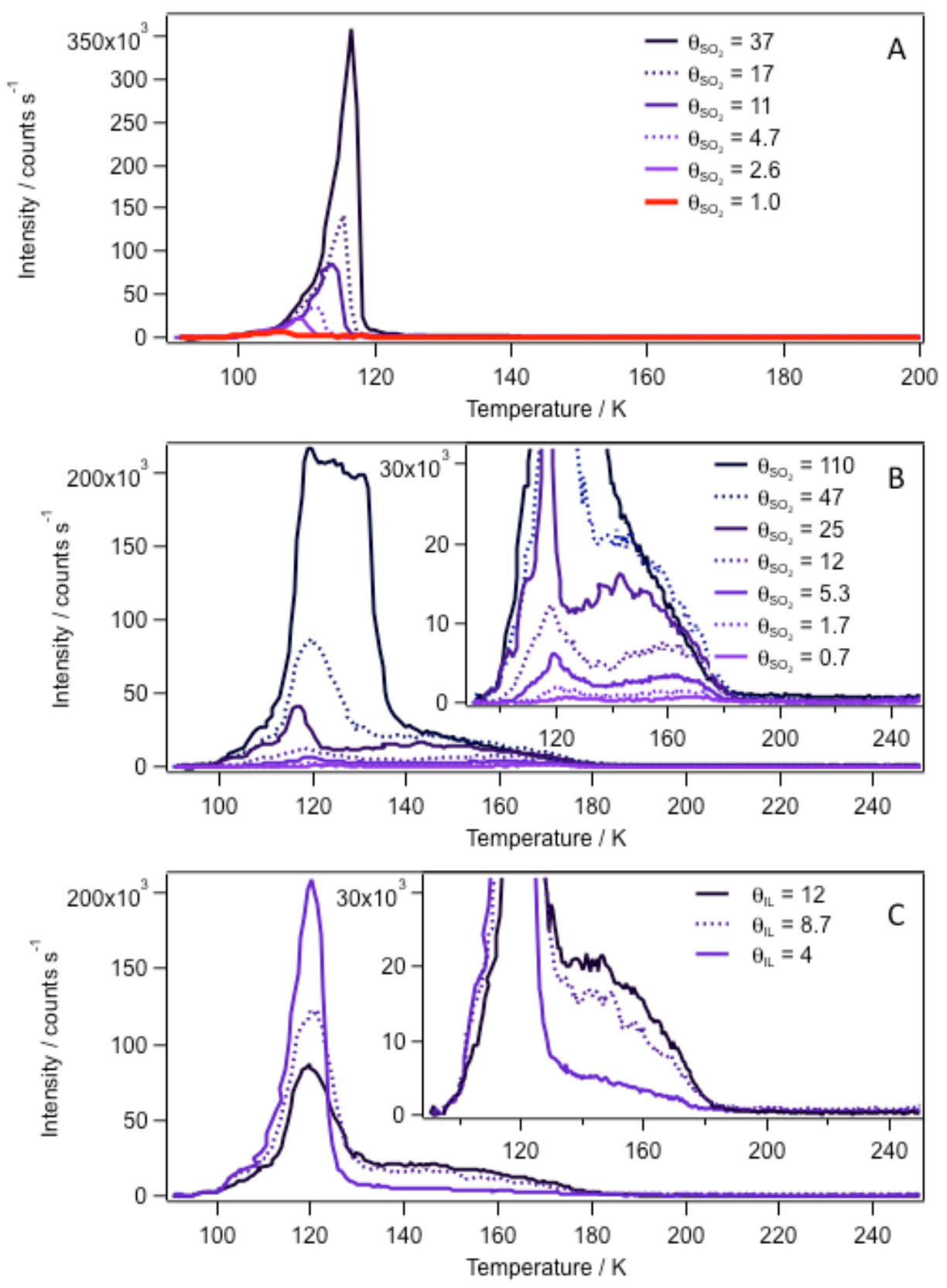

Figure 7. A, TPD of pure $\mathrm{SO}_{2}$ from CCAu using $m / z=64$. B, TPD of increasing coverages of $\mathrm{SO}_{2}(0.7 \leq$ $\left.\theta_{S O 2} \leq 110\right)$ co-adsorbed with IL snow $\left(\theta_{I L}=10\right)$, inset shows expanded intensity scale. C, TPD of increasing coverages of IL $\left(\theta_{I L}=4.0,8.7\right.$ and 12$)$ co-adsorbed with a fixed amount of $\mathrm{SO}_{2}\left(\theta_{\mathrm{SO}_{2}}=50 \pm 4\right)$, inset shows expanded intensity scale. 
The high temperature states from $130-180 \mathrm{~K}$ for all three $\mathrm{SO}_{2}$ coverages in Fig. $7 \mathrm{C}$ were fitted using the sum of seven simulated first order states with activation energies that incremented by $2 \mathrm{~kJ} \mathrm{~mol}^{-1}$ using $A=$ $6 \times 10^{14} \mathrm{~s}^{-1}$. The fit for $\theta_{I L}=12$ is shown in Fig. 8A while Fig. 8B shows the distribution of states as plots of initial $\mathrm{SO}_{2}$ coverage versus activation energy. The shape of the distribution remains the same but simply increases as the IL coverage increases. A plot of the total stabilised $\mathrm{SO}_{2}$ coverage versus IL coverage was linear within error with a gradient of $\theta_{S O 2}$ stab $/ \theta_{I L}=1.9$, i.e. approximately two layers of $\mathrm{SO}_{2}$ were stabilised per layer of IL.

We suggest the following explanation for this behaviour. As the components were co-adsorbed there was no pre-existing IL structure and the $\mathrm{SO}_{2}$ and IL were intimately mixed. The $\mathrm{SO}_{2}$ is able to diffuse below $130 \mathrm{~K}$ allowing it to move and form stabilised regions where the $\mathrm{SO}_{2}$ interacts with the ionic parts of the IL. The remaining $\mathrm{SO}_{2}$ is left residing in areas where the octyl chains exist, or consolidating into solid $\mathrm{SO}_{2}$. In figure $7 \mathrm{C}$ which has a fixed but relatively low amount of $\mathrm{SO}_{2}\left(\theta_{\mathrm{SO} 2}=50\right)$ the behaviour is simple, with a single peak at $120 \mathrm{~K}$ which decreases in intensity, and the stabilised states from $130-180 \mathrm{~K}$ which increase in intensity, as the IL concentration increases. The peak at $120 \mathrm{~K}$ is slightly stabilised relative to pure $\mathrm{SO}_{2}$ desorption, so we suggest that $\mathrm{SO}_{2}$ interactions with alkyl chains are somewhat stronger than $\mathrm{SO}_{2}-\mathrm{SO}_{2}$ interactions. After desorption of the $\mathrm{SO}_{2}$ associated with the alkyl chains, the stabilised $\mathrm{SO}_{2}$ associated with the IL ion pairs is now compact enough that it can be regarded as a porous structure with stabilised $\mathrm{SO}_{2}$ within the pores, similar to Fig. 6C. Further heating allows the stabilised $\mathrm{SO}_{2}$ to desorb. However, when the adlayer is very thick with $\theta_{S O 2}=110$ and $\theta_{I L}=10$, Fig. 7B, the low temperature peak broadens into a flat topped peak which drops in intensity at a much higher temperature; compare with $\theta_{I L}$ $=4$ and $\theta_{\mathrm{SO} 2}=50$ in Fig. $7 \mathrm{C}$, which has a similar ratio of $\mathrm{SO}_{2}$ to $\mathrm{IL}$, but very different behaviour of the low temperature peak. We think this can be explained as follows. Initial desorption from the thick mixed layer occurs from the top layers as $\mathrm{SO}_{2}$ desorbing from the alkyl chain areas. As this occurs it forms a more compact layer of IL containing stabilised $\mathrm{SO}_{2}$ above lower layers which still contain $\mathrm{SO}_{2}$ associated with alkyl chains. This compact layer presents a barrier to desorption of the weakly bound $\mathrm{SO}_{2}$ which causes it to desorb at a higher temperature, causing the flat topped peak as follows. First the stabilised $\mathrm{SO}_{2}$ starts to desorb from the top layers at about $130 \mathrm{~K}$. This opens up channels through which $\mathrm{SO}_{2}$ from below can desorb, which maintains a high rate of desorption. As the temperature rises, more stabilised $\mathrm{SO}_{2}$ desorbs opening more channels and maintaining a high desorption rate. By $135 \mathrm{~K}$ the more weakly bound $\mathrm{SO}_{2}$ becomes exhausted, giving the abrupt drop on the high temperature side of the peak. The main difference between the acetone situation and the $\mathrm{SO}_{2}$ situation, was that the acetone diffused into and out of a pre-formed IL porous structure, whereas the $\mathrm{SO}_{2}$ was co-adsorbed with the IL which led to a relatively impervious layer of IL/stabilised $\mathrm{SO}_{2}$ capping more weakly bound $\mathrm{SO}_{2}$ below. 

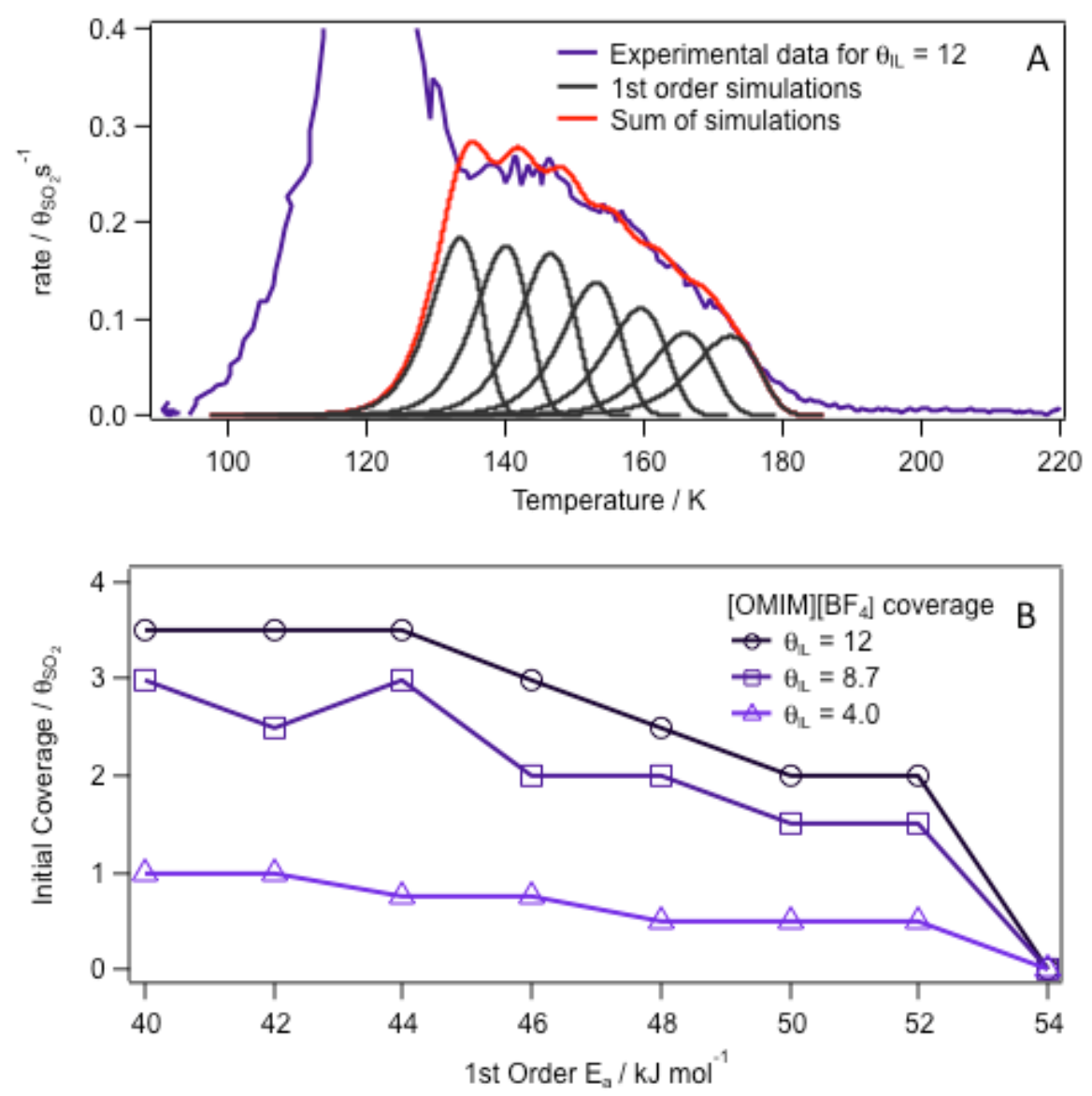

Figure 8. A, TPD of IL $\left(\theta_{I L}=12\right)$ co-adsorbed with $\mathrm{SO}_{2}\left(\theta_{S O 2}=50 \pm 4\right)$ fitted with the sum of seven first order TPD curves. B, initial coverages versus first order activation energies for the simulated fits to the desorption curve for $\theta_{I L}=4,8.7$, and 12 when co-adsorbed with, $\theta_{S O 2}=50 \pm 4$ in the range to $130 \mathrm{~K}<T<$ $180 \mathrm{~K}$.

The general shape of the curves in Fig.8B are similar to those for acetone, Fig. 5B, having a high density of states at low values of $E_{a}$ that decreases as $E_{a}$ increases before dropping abruptly to zero beyond the highest $E_{a}$. However, for acetone a particularly high density state was observed at the highest $E_{a}$ for $\theta_{I L}=$ 34 , possibly due to the formation of an ionic underlayer in the IL at this high coverage. For the $\mathrm{SO}_{2}$ work the highest IL coverage was $\theta_{I L}=12$, well below where the change was thought to occur, so it is possible that a similar stabilised state for $\mathrm{SO}_{2}$ may exist at $E_{a}=52 \mathrm{~kJ} \mathrm{~mol}^{-1}$ for $\theta_{I L}=34$.

For acetone the maximum desorption energy was $1.6 \mathrm{x}$ the multilayer desorption energy. For $\mathrm{SO}_{2}$ the maximum desorption energy was also 1.6x the multilayer value. Both are significant stabilisations. For the stabilised $\mathrm{SO}_{2}$ above $130 \mathrm{~K}, \theta_{\mathrm{SO} 2} / \theta_{I L}=1.9$ which, using the molar volumes of the materials as described for acetone, corresponds to approximately $6 \mathrm{SO}_{2}$ molecules per IL ion pair. This is much 
higher than the acetone value of $\approx 1.1$ acetone per IL ion pair. The difference may be due to using coadsorption for $\mathrm{SO}_{2}$.

\subsection{Desorption of $\mathrm{H}_{2} \mathrm{O}$}

TPD of $\mathrm{H}_{2} \mathrm{O}$ was monitored using the parent ion, $\mathrm{H}_{2} \mathrm{O}^{+}(m / z=18)$. Although the $\mathrm{OH}^{+}(m / z=17)$ gave the same TPD profile as $\mathrm{H}_{2} \mathrm{O}^{+}$, it was not used as it was superimposed on a background which was $\approx 50 \%$ of the maximum signal. This background was unrelated to desorption from the sample and probably originated from within the ionisation region of the mass spectrometer. Figure 9A shows TPD scans of pure $\mathrm{H}_{2} \mathrm{O}$ from the CCAu surface for initial coverages of $\theta_{\mathrm{H} 2 \mathrm{O}}=1-821$. As for the other adsorbates, $\theta_{\mathrm{H} 2 \mathrm{O}}$ $=1$ was defined as the highest coverage that exhibited a first order desorption profile, see ESI. The TPD curve for a monolayer of water could be fitted with $E_{a}=47(1) \mathrm{kJ} \mathrm{mol}^{-1}$ and a pre-exponential of $2 \times 10^{15(0.5)}$. This first order desorption peak evolved into a zero order peak up to $\theta_{H 2 O}=10$, but for higher coverages ( $\operatorname{see} \theta_{H 2 O}=31$ ) there was a decrease in the desorption rate at $\approx 150 \mathrm{~K}$, followed by a return to zero order kinetics for higher temperatures. The decrease in the leading edge intensity is due to a solid state phase change from amorphous ice at low temperature to crystalline ice at higher temperature ${ }^{24}$. The low temperature side due to amorphous ice, $\theta_{\mathrm{H} 2 \mathrm{O}}=31$, was fitted using the leading edge and simulated, see ESI, giving $E_{a}=49(5) \mathrm{kJ} \mathrm{mol}^{-1}$ and a pre- exponential of $3 \times 10^{17(2)} \mathrm{s}^{-1}$. A similar leading edge fit and simulation to the high temperature, crystalline phase, $\theta_{H 2 O}=821$, gave $E_{a}=43(1) \mathrm{kJ} \mathrm{mol}^{-1}$ and a pre-exponential of $2 \times 10^{15(0.5)} \mathrm{s}^{-1}$. The phase transition occurs at $\theta_{H 2 O}=8-10$.

TPD plots of increasing amounts of water co-adsorbed with $\theta_{I L}=10$ at $90 \mathrm{~K}$ are shown in Fig. 9B. For $\theta_{\mathrm{H} 2 \mathrm{O}}=16-32$ a broad peak grows from $140 \mathrm{~K}-175 \mathrm{~K}$. For $\theta_{\mathrm{H} 2 \mathrm{O}}=62-117$ a double peak structure emerges over the same temperature region, and for high initial coverages, $\theta_{H 2 O}=278-864$ the peak grows and moves to higher temperature, reaching $190 \mathrm{~K}$ for the highest coverage.

For initial coverages up to $\theta_{H 2 O}=117$ the water appears to be filling an identifiable range of states. For $\theta_{\mathrm{H} 2 \mathrm{O}}=117$ there is a stabilised peak at $T \approx 170 \mathrm{~K}$, and another peak at $\mathrm{T} \approx 155 \mathrm{~K}$ which is very similar to that for pure water desorption and so essentially non-stabilised. Using the molar volume for water $(1.80 \mathrm{x}$ $10^{-5} \mathrm{~m}^{3} \mathrm{~mol}^{-1}$ ) the surface concentration of an average water monolayer is $1.04 \times 10^{19}$ molecules $\mathrm{m}^{-2}$ for $\theta_{H 2 O}=1$ while for the IL it is $1.78 \times 10^{18}$ molecules $\mathrm{m}^{-2}$ for $\theta_{I L}=1$ (see acetone section for the calculation). So for $\theta_{H 2 O}=117$ and $\theta_{I L}=10, \theta_{H 2 O} / \theta_{I L}=11.7$ which corresponds to $\approx 68$ water molecules per ion pair. This is a rather large number of water molecules for each ion pair and not consistent with any idea of a solid, porous IL structure being responsible for the states between 140 and $175 \mathrm{~K}$ for $\theta_{H 2 O}=$ 117. For $\theta_{H 2 O}=278-864$ it is no longer possible to discern two peaks, the entire peak growing in 
intensity and moving to higher temperature as the water coverage increases. For the highest coverage, $\theta_{H 2 O}=864$, a broad intense peak grows at $\approx 180 \mathrm{~K}$. We concentrate our analysis on the $\theta_{H 2 O}=338$ and 864 curves, Fig. 10.
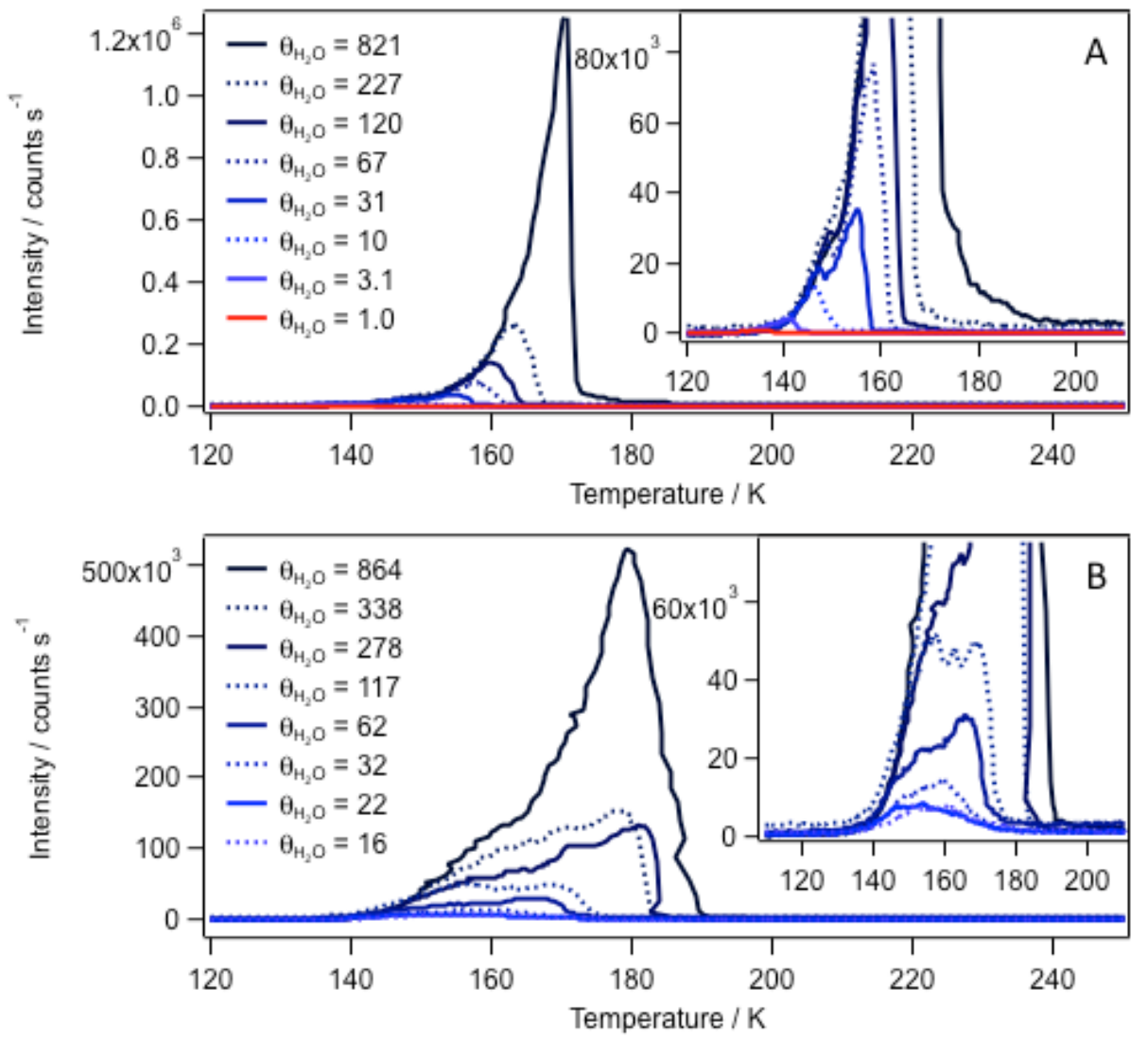

Figure 9. TPD of $\mathrm{H}_{2} \mathrm{O}$ using $m / z=18$. A, TPD of pure $\mathrm{H}_{2} \mathrm{O} 1 \leq \theta_{\mathrm{H} 2 \mathrm{O}} \leq 821$ ) from CCAu, inset shows expanded intensity scale. $\mathrm{B}$, TPD of increasing coverages of $\mathrm{H}_{2} \mathrm{O}\left(16 \leq \theta_{\mathrm{SO} 2} \leq 864\right)$ co-adsorbed with IL snow $\left(\theta_{I L}=10\right)$, inset shows expanded intensity scale.

The $\theta_{H 2 O}=338$ peak can be simulated approximately, Fig. 10A, using zero order desorption and a linear change in $E_{a}$ from $42 \rightarrow 50 \mathrm{~kJ} \mathrm{~mol}^{-1}$. Similarly, the $\theta_{H 2 O}=864$ peak can be simulated with zero order desorption and a single linear change in $E_{a}$ from $42-57 \mathrm{~kJ} \mathrm{~mol}^{-1}$, Fig. 10A, but only up to about $164 \mathrm{~K}$, after which the simulation fails completely. For both initial coverages, $E_{a}$ is $42 \mathrm{~kJ} \mathrm{~mol}^{-1}$ at the initial coverage. For the higher coverage surface $E_{a}$ rises far too quickly for $\theta_{H 2 O}<700$ (where $T>164 \mathrm{~K}$ ) in Fig. 10B leading to the low and constant simulated rate in Fig. 10A. By using two linear changes in $E_{a}$ which switch from one to the other at a given temperature, $164 \mathrm{~K}$, Fig. 10B, rather than at a given coverage, the simulations show a good fit to experiment for $\theta_{\mathrm{H} 2 \mathrm{O}}=338$, and an reasonably good fit for $\theta_{\mathrm{H} 2 \mathrm{O}}=864$, Fig. 10A. Below $164 \mathrm{~K}$, the activation energy range is $42 \rightarrow 45 \mathrm{~kJ} \mathrm{~mol}^{-1}$, increasing for decreasing coverage. Above $164 \mathrm{~K}$ the activation energy is $45 \rightarrow 49$ or $48 \mathrm{~kJ} \mathrm{~mol}^{-1}$, still increasing for decreasing coverage but the gradient is more shallow for the higher coverage surface than for the lower 
coverage surface. This means that at zero coverage the activation energies for both initial coverages are about the same, at 48-49 $\mathrm{kJ} \mathrm{mol}^{-1}$, as one would expect. For sufficiently high coverages of water, one might expect $E_{a}$ to tend to the value for pure amorphous water $\left(49 \mathrm{~kJ} \mathrm{~mol}^{-1}\right)$ for the initial stages of desorption below $150 \mathrm{~K}$. However, for the highest coverage used here, $E_{a} \approx 42 \mathrm{~kJ} \mathrm{~mol}^{-1}$ which is the same as the activation energy for pure, crystalline water, implying that the water is already crystalline at low desorption temperatures due to the presence of the IL. For all of these simulations a pre-exponential of $\mathrm{A}=10^{15}$ was used as this is the pre-exponential used for the pure crystalline water. As desorption proceeds, and the water coverage drops, the IL concentration increases causing the stabilisation of the water to increase, as observed by the increasing value of $E_{a}$. For water coverages $\theta_{H 2 O}<50$ during the final stages of desorption, the water is stabilised at about $48-49 \mathrm{~kJ} \mathrm{~mol}^{-1}$ which may correspond to the IL ion pairs moving to surround water molecules and hence provide strong stabilisation.
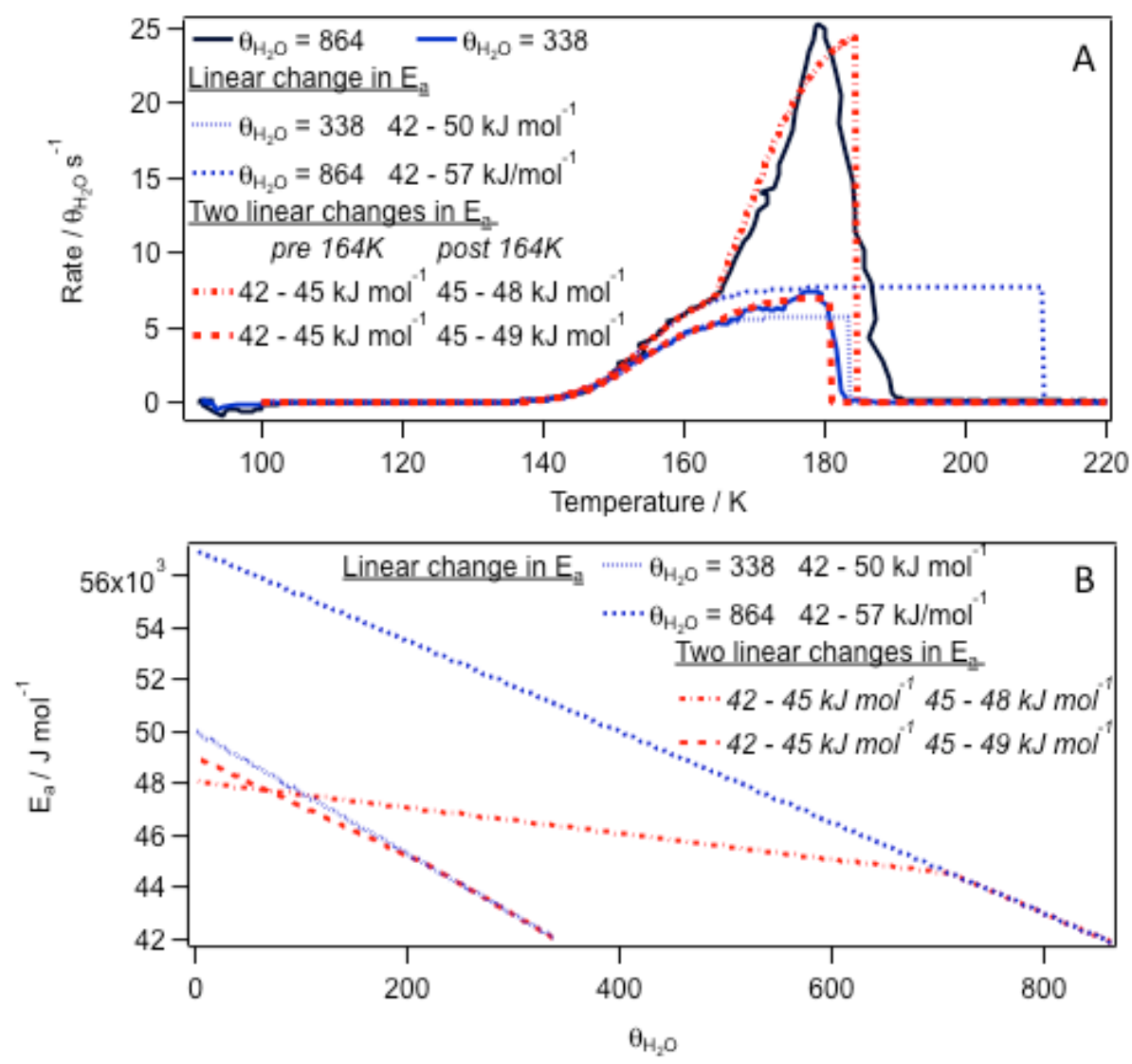

Figure 10. A, TPD curves measured using $m / z=18$ for $\theta_{H 2 O}=338$ and 864 co-adsorbed with $\theta_{I L}=10$ at $90 \mathrm{~K}$, fitted with single linearly changing $\mathrm{E}_{\mathrm{a}}$, and double linear changes in $\mathrm{E}_{\mathrm{a}}$. B, activation energy $\mathrm{E}_{\mathrm{a}}$ versus coverage, $\theta_{H 2 O}$, for the single and double linear changes. For the double linear changes, $\mathrm{E}_{\mathrm{a}}$ switches from the steeper to the shallower gradient at $164 \mathrm{~K}$, as desorption occurs.

All the water in the $\theta_{H 2 O}=864$ curve is stabilised to some degree by the ionic liquid which has a coverage of $\theta_{I L}=10$, giving $\theta_{H 2 O} / \theta_{I L} \approx 80$. This corresponds to $\approx 505$ water molecules per ion pair, 
which is a long range effect. For $\mathrm{SO}_{2}$ a somewhat similar flattening and broadening of the desorption curve was observed for thick adlayers where it was argued that desorption from the outer layers formed a relatively impermeable outer layer of saturated porous IL, which then retarded desorption of species from below. However, for the high coverages of water here, the IL is so low in concentration, that it seems impossible that the ion pairs could coalesce to form a similar outer layer of saturated porous IL. The change in gradient of $E_{a}$ versus $\theta_{H 2 O}$ occurs at $164 \mathrm{~K}$. For the initial coverage $\theta_{\mathrm{H} 2 \mathrm{O}}=864$ this occurs at $\theta_{H 2 O} / \theta_{I L} \approx 70$, so it is not possible to argue that it has anything to do with a structural change in the ionic liquid. We suggest the following to explain the change in $E_{a}$ versus $\theta_{H 2 O}$. When the IL and water were deposited at $90 \mathrm{~K}$, the IL arrived as ion pairs and became embedded within excess water as separate ion pairs. The IL therefore interacted with the surrounding water via a dipole field to stabilise it. Water close to the octyl chain would be destabilised. As the temperature increased water desorbed and the IL dipoles became relatively denser within the water matrix, but the IL dipoles were still isolated from each other. At $164 \mathrm{~K}$, the ion pairs dissociate into separate ions ${ }^{23}$ and can move apart such that each is surrounded by stabilised water molecules. The electric field of the ions is longer range than that of a dipole, so more water at greater distance from the ions can be stabilised. This leads to the flattening of the gradient of $E_{a}$ versus $\theta_{\mathrm{H} 2 \mathrm{O}}$ as the longer range interaction means a slower change in $E_{a}$ with coverage.

\section{Discussion and Conclusion}

The ionic liquid [OMIM] $\left[\mathrm{BF}_{4}\right]$ when deposited from the vapour at $90 \mathrm{~K}$, forms a highly porous solid structure. The interior surfaces of the pores have a range of compositions from being lined with the ionic parts of the cations and anions, through a mixture of ions and octyl chains, to pores lined predominantly with octyl chains. These pores provide a continuum of adsorption states which can stabilise or destabilise an adsorbate relative to the bonding in the pure material. We associate the stabilised states with adsorption onto the ionic parts of the ionic liquid, and the destabilised states with adsorption onto the octyl chains. Acetone adsorbed on top of this porous structure interacts with the IL surface and is able to diffuse some way into it, equivalent to about five layers of the IL. By adsorbing acetone below the porous IL structure, the acetone is forced to pass through it during desorption allowing all the pores to be occupied. This gives stabilised acetone over an energy range of 45 to $61 \mathrm{~kJ} \mathrm{~mol}^{-1}$, compared with the activation energy for desorption of pure acetone of $38 \mathrm{~kJ} \mathrm{~mol}^{-1}$. The total amount of stabilised acetone was 1.1 acetone molecule per IL ion pair. Destabilised acetone was also observed as relatively sharp desorption peaks at temperatures below that for pure acetone desorption. These were attributed to acetone adsorbed in pores lined predominantly with octyl chains. During desorption the density of highly stabilised states at $61 \mathrm{~kJ} \mathrm{~mol}^{-1}$ grew for IL coverage between 20 and 35 layers. This was attributed to either the formation of a disordered ionic underlayer at the surface of the IL where the interaction of acetone with the ions would be strongest, or possibly a more general structural change in the IL due to 
dissociation of the ion pairs ${ }^{23}$ into separate ions, causing a general increase in the number of these highly stabilised sites.

Sulfur dioxide and water were each co-adsorbed with the IL at $90 \mathrm{~K}$ to maximise the interactions between the two. For $\mathrm{SO}_{2}$ a well defined set of stabilised states from 40 to $54 \mathrm{~kJ} \mathrm{~mol}^{-1}$ were observed, compared to $32 \mathrm{~kJ} \mathrm{~mol}^{-1}$ for pure $\mathrm{SO}_{2}$. The total number of $\mathrm{SO}_{2}$ molecules in these stabilised states was $6 \mathrm{SO}_{2}$ molecules per IL ion pair. These stabilised states occurred for $\mathrm{SO}_{2}$ to $\mathrm{IL}$ coverages ratios which might reasonably lead to the formation of a porous IL structure. For higher $\mathrm{SO}_{2}$ to IL coverage ratios, where the IL ion pairs are embedded in a matrix of $\mathrm{SO}_{2}$, an intense, flat topped, broad desorption peak was observed. This was thought to be due to the formation of an outer, relatively impervious layer of porous IL which still containing stabilised $\mathrm{SO}_{2}$ within the pores. This layer prevented destabilised $\mathrm{SO}_{2}$ from deeper in the surface from desorbing until stabilised $\mathrm{SO}_{2}$ starts to desorb which open up channels for desorption of $\mathrm{SO}_{2}$ from below.

For water which was co-adsorbed with the IL at $90 \mathrm{~K}$, there appeared to be a range of stabilised states, but these corresponded to $\approx 68$ water molecules per ion pair and hence could not be attributed to any kind of porous IL structure. For very large water coverages of $\approx 505$ water molecules per ion pair, virtually all the water was stabilised to some degree with an activation energy that increased with decreasing coverage. The activation energy changed linearly with decreasing coverage from 42 to $45 \mathrm{~kJ} \mathrm{~mol}^{-1}$ and then from 45 to $49 \mathrm{~kJ} \mathrm{~mol}^{-1}$. The switch between the two linear regimes occurring at $164 \mathrm{~K}$. We associate the lower energy change with IL ion pairs embedded within a matrix of water, the energy rising with decreasing coverage as the proportion of water lying close to the ion pair dipole increases. At $164 \mathrm{~K}$ the ion pairs dissociate into separate ions providing a stronger, longer range interaction with the surrounding water which accounts for the higher energy change. Pure water had desorption energies of $49 \mathrm{~kJ} \mathrm{~mol}^{-1}$ for the amorphous phase and $43 \mathrm{~kJ} \mathrm{~mol}^{-1}$ for the crystalline phase which virtually covers the energy range for the water/IL mixtures. So rather than particularly stabilising the water, the IL tends to modify the hydrogen bonding network of pure water.

\section{Acknowledgements}

Funding from the Engineering and Physical Science Research Council, U.K. (EP/I018093/1) is gratefully acknowledged. We thank P. Licence for providing the ionic liquid.

\section{References}


1. J. M. Crosthwaite, M. J. Muldoon, J. K. Dixon, J. L. Anderson and J. F. Brennecke, J. Chem. Thermodyn., 2005, 37, 559-568.

2. A. Deyko, K. R. J. Lovelock, P. Licence and R. G. Jones, Phys. Chem. Chem. Phys., 2011, 13, 16841-16850.

3. S. G. Hessey and R. G. Jones, Chem. Sci., 2013, 4, 2519-2529.

4. L. Y. Ma, M. Yang and K. S. Zhao, Journal of Molecular Liquids, 2016, 220, 295-303.

5. C. P. Zhai, J. J. Wang, X. P. Xuan and H. Q. Wang, Acta Physico-Chimica Sinica, 2006, 22, 456459.

6. W. Y. Tao, P. Lin, S. L. Liu, Q. J. Xie, S. M. Ke and X. R. Zeng, Sensors, 2017, 17.

7. G. Severa, K. Bethune, R. Rocheleau and S. Higgins, Chemical Engineering Journal, 2015, 265, 249-258.

8. M. J. Jin, Y. C. Hou, W. Z. Wu, S. H. Ren, S. D. Tian, L. Xiao and Z. G. Lei, J. Phys. Chem. B, 2011, 115, 6585-6591.

9. A. F. Ghobadi, V. Taghikhani and J. R. Elliottt, Journal of Physical Chemistry B, 2011, 115, 13599-13607.

10. M. Reis, R. E. Leitao and F. Martins, Journal of Chemical and Engineering Data, 2010, 55, 616620.

11. J. L. Anthony, E. J. Maginn and J. F. Brennecke, Journal of Physical Chemistry B, 2001, 105, 10942-10949.

12. K. R. J. Lovelock, E. F. Smith, A. Deyko, I. J. Villar-Garcia, P. Licence and R. G. Jones, Chem. Commun., 2007, 4866-4868.

13. A. Deyko and R. G. Jones, Faraday Discuss., 2012, 154, 265-288.

14. J. P. Armstrong, C. Hurst, R. G. Jones, P. Licence, K. R. J. Lovelock, C. J. Satterley and I. J. VillarGarcia, Physical Chemistry Chemical Physics, 2007, 9, 982-990.

15. K. R. J. Lovelock, A. Deyko, J.-A. Corfield, P. N. Gooden, P. Licence and R. G. Jones, ChemPhysChem, 2009, 10, 337-340.

16. V. N. Emel'yanenko, S. P. Verevkin, A. Heintz, J.-A. Corfield, A. Deyko, K. R. J. Lovelock, P. Licence and R. G. Jones, J. Phys. Chem. B, 2008, 112, 11734-11742.

17. K. R. J. Lovelock, A. Deyko, P. Licence and R. G. Jones, Phys. Chem. Chem. Phys., 2010, 12, 8893-8901.

18. A. Deyko, K. R. J. Lovelock, J.-A. Corfield, A. Taylor, P. N. Gooden, I. J. Villar-Garcia, P. Licence, R. G. Jones, V. G. Krasovskii, E. A. Chernikova and L. M. Kustove, Phys. Chem. Chem. Phys., $2009,11,8544-8555$.

19. A. W. Taylor, K. R. J. Lovelock, A. Deyko, P. Licence and R. G. Jones, Physical Chemistry Chemical Physics, 2010, 12, 1772-1783.

20. S. G. Hessey and R. G. Jones, Surf. Interface Anal., 2015, 47, 587-600.

21. M. Buckley, PhD, Nottingham, PhD 2016.

22. R. Foulston, S. Gangopadhyay, C. Chiutu, P. Moriarty and R. G. Jones, Phy. Chem. Chem. Phys., 2012, 14, 6054-6066.

23. K. L. Syres and R. G. Jones, Langmuir, 2015, DOI: 10.1021/acs.langmuir.5b02932.

24. W. A. Brown and A. S. Bolina, Monthly Notices of the Royal Astronomical Society, 2007, 374, 1006-1014. 